IZA DP No. 6343

The Firm as the Locus of Social Comparisons: Internal Labor Markets versus Up-or-Out

Emmanuelle Auriol

Guido Friebel

Frauke Lammers

February 2012 


\title{
The Firm as the Locus of Social Comparisons: Internal Labor Markets versus Up-or-Out
}

\author{
Emmanuelle Auriol \\ Toulouse School of Economics \\ and CEPR \\ Guido Friebel \\ Goethe University Frankfurt, \\ CEPR and IZA \\ Frauke Lammers \\ University of Bern
}

Discussion Paper No. 6343

February 2012

\author{
IZA \\ P.O. Box 7240 \\ 53072 Bonn \\ Germany \\ Phone: +49-228-3894-0 \\ Fax: +49-228-3894-180 \\ E-mail: iza@iza.org
}

Any opinions expressed here are those of the author(s) and not those of IZA. Research published in this series may include views on policy, but the institute itself takes no institutional policy positions.

The Institute for the Study of Labor (IZA) in Bonn is a local and virtual international research center and a place of communication between science, politics and business. IZA is an independent nonprofit organization supported by Deutsche Post Foundation. The center is associated with the University of Bonn and offers a stimulating research environment through its international network, workshops and conferences, data service, project support, research visits and doctoral program. IZA engages in (i) original and internationally competitive research in all fields of labor economics, (ii) development of policy concepts, and (iii) dissemination of research results and concepts to the interested public.

IZA Discussion Papers often represent preliminary work and are circulated to encourage discussion. Citation of such a paper should account for its provisional character. A revised version may be available directly from the author. 


\section{ABSTRACT}

\section{The Firm as the Locus of Social Comparisons: Internal Labor Markets versus Up-or-Out ${ }^{*}$}

We suggest a parsimonious dynamic agency model in which workers have status concerns. A firm is a promotion hierarchy in which a worker's status depends on past performance. We investigate the optimality of two types of promotion hierarchies: (i) internal labor markets, in which agents have a job guarantee, and (ii) "up-or-out", in which agents are fired when unsuccessful. We show that up-or-out is optimal if success is difficult to achieve. When success is less hard to achieve, an internal labor market is optimal provided the payoffs associated with success are moderate. Otherwise, up-or-out is, again, optimal. These results are in line with observations from academia, law firms, investment banks and top consulting firms. Here, up-or-out dominates, while internal labor markets dominate where work is less demanding or payoffs are more compressed, for instance, because the environment is less competitive. We present some supporting evidence from academia, comparing US with French economics departments.

JEL Classification: J3, M5, L2

Keywords: status, promotion hierarchies, incentives, sorting

Corresponding author:

Guido Friebel

Goethe University Frankfurt

Chair of Human Resource Management

P.O. Box 52

Grüneburgplatz 1

60629 Frankfurt

Germany

E-mail: gfriebel@wiwi.uni-frankfurt.de

\footnotetext{
* We would like to thank seminar and conference participants in Bonn, the Personnel Economics Conference in Trier, the Rotterdam TI / Mannheim ZEW workshop on Social Relations and Incentives in the Workplace, and the Bad Homburg Workshop on Organizational Economics. In particular we thank Robert Dur, Matthias Kräkel, Susanne Neckermann, and Ferdinand von Siemens for helpful suggestions. All errors are our own. Auriol and Friebel gratefully acknowledge support from ANR and DFG, Lammers from the Volkswagen Foundation. Parts of the paper were written while Lammers was visiting the Toulouse School of Economics. All errors are ours.
} 


\section{Introduction}

Status is an important determinant for human behavior, a proposition that is supported by psychologists and economists alike (e.g. Frank, 1988, Huberman et al., 2004, Moldovanu et al., 2007). Status concerns are particularly important at work; people spend much of their time at the workplace, and their behavior at work is an important determinant of an economy's efficiency. The goal of gaining higher status in an organization motivates people to work hard for long periods of time; examples from the academic world, law firms, investment banks, and consulting firms abound. Making partner at a law firm, or getting tenure in a university provides much stronger motivation than just getting a wage rise.

Chester Barnard (1938, p.145), the first modern management theorist, was well aware of the relevance of status for motivation and the necessity to provide both monetary rewards and status: "Even in strictly commercial organizations, where it is least supposed to be true, money without distinction, prestige, position, is so utterly ineffective that it is rare that greater income can be made to serve even temporarily as an inducement if accompanied by surpression of prestige." Peter Drucker (1954, p. 154) expressed similar thoughts: "But financial rewards are not enough. People, whether managers or workers, whether in business or outside, need rewards of prestige and pride." Indeed, most organizations do not only provide monetary incentives, but they also allocate status between workers by giving them awards, office space, company cars, and, arguably most importantly, promotions.

Given the prominence of status concerns and the widespread use of promotion hierarchies, it is surprising that there are only a few papers in economics that have investigated the design of organizations and incentive contracts in the presence of status concerns (Auriol and Renault 2001, 2008, and Besley and Ghatak, 2008). ${ }^{1}$ The main result of Auriol and Renault (2001, 2008) is that junior workers should get minimal status and fixed wage, and no bonus; their work incentives come solely from the perspective of getting a promotion. This result,

\footnotetext{
${ }^{1}$ Status in Auriol and Renault $(2001,2008)$ and Besley and Ghatak (2008) is different from Moldovanu et al. (2007), in which money is the source of status. As we are interested in organizational design, it is natural to focus on rank in a hierarchy as the source for status.
} 
however, is derived in a model in which firms do not fire workers if they are unsuccessful. In reality, there are two dominant forms of promotion hierarchies, the "internal labor market" and the "up-or-out system". Doeringer and Piore (1971) remarked that firms maintain internal labor markets in which there are job guarantees, incentives are given through promotion hierarchies, and wages are associated to job titles (see for instance, Baker et al., 1994). "Up-or-out" exposes employees to more risk and steeper incentives. Employees work for some years as juniors with the explicit or implicit understanding that upon completion of this phase, they will either be promoted or will have to leave the firm.

We extend the Auriol and Renault $(2001,2008)$ framework to provide an explicit comparison of internal labor markets with up-or-out systems. We derive these hierarchies as solutions to a simple dynamic agency model, describe their properties in terms of profits, wages paid to juniors and seniors, and the span of control implied. We determine when one or the other is optimal, generate some empirical predictions, and collect supporting evidence. We also consider heterogeneous workers and endogenize workers' outside options by considering self-employment opportunities.

An important literature has looked at the rationale for firms to maintain internal labor markets, ${ }^{2}$ and up-or-out has attracted much attention among economists as well. ${ }^{3}$ However, most of the literature on internal labor markets and up-or-out argues that promotion hierarchies solve contracting issues related to non-verifiable output and specific human capital accumulation. In our theory, output is verifiable, and promotion hierarchies are designed in response to human beings' need for status. Indeed, in many sectors in which up-or-out is applied, output is readily observable and verifiable. In academia, the research output of individuals is not only used as the basis for the promotion decisions taken by the university, but also for the allocation of public funds (e.g. in Germany and the UK). In particular, in the natural sciences or economics, the "value" of a scientist in terms of scientific output can

\footnotetext{
${ }^{2}$ For surveys of the theoretical and empirical literature, see Gibbons and Waldman (1999), and Waldman (2009).

${ }^{3}$ Below we review the relationship to the following papers: Demougin and Siow (1994), O'Flaherty and Siow (1995), Kahn and Huberman (1988), Waldman (1990), Ghosh and Waldman (2010).
} 
be determined pretty neatly by looking at their CV. The same is true for investment bankers (the return on the funds invested or the profits generated) or lawyers (size and frequency of cases won, or clients acquired).

In our model, there is one large firm that offers workers either an internal labor market, or up-or-out. Workers can choose to be self-employed or to work in the large firm. Three different employment forms are hence generated from the same model: self-employment, internal labor markets, and up-or-out systems. By working in the promotion hierarchy, workers receive the opportunity of gaining additional status. The firm allocates status among workers by means of job titles or ranks. For incentive purposes, all juniors enjoy the same low status and successful agents receive a large increase in status through promotions. In equilibrium, only productive agents enter the large firm and as everyone exerts the same effort, workers take a status gamble. Self-employment, in which there is no reallocation of status, ${ }^{4}$ is preferred by less productive workers, because they have little to gain from competing for status and incentive pay with more productive types. Thus, promotion hierarchies function as a screening device ensuring that only productive workers enter a firm, and firms make profits by using promotion hierarchies. ${ }^{5}$

The large firm makes profits because junior workers receive wages below the output they produce. They enjoy little status, but they face steep incentives by the prospect of receiving both a large fixed wage, a substantial bonus and high status in the firm when promoted upon a success. Thus, both junior and senior workers are exerting more effort than in self-employment. These productivity gains are shared between the firm and the successful workers who are promoted. An entrepreneur who would hire only one worker or hire more than one worker without differentiating their status would not make profits because workers have the alternative to be self-employed.

\footnotetext{
${ }^{4}$ Notice that we are not saying that there are no social status concerns of self-employed, as the market for Rolex or Porsche demonstrates. However, such external symbols are different from the internal status symbols like promotions. Internal status can be controlled by the firm and is, consequently, an element of organizational design, which is the focus of our paper.

${ }^{5}$ This is a similar mechanism as the one in von Siemens (2010) in which a firm can prevent inequity-averse low-ability workers from entering by not compensating them for rent differences within the firm.
} 
We derive the optimal incentive and promotion scheme both for internal labor markets and for up-or-out systems. We identify the situations in which internal labor markets and those in which up-or-out contracts are optimal. We find that in terms of the profits of the firm, up-or-out is always optimal if it is very difficult to achieve a success. When success is less hard to achieve, the internal labor market is optimal provided the payoff associated with success is small enough. Otherwise up-or-out is, again, optimal. The results are in line with observations that up-or-out is the predominant system in modern academia, law firms, investment banks, and top consulting firms, while internal labor markets dominate where work is less demanding and where payoffs are more compressed, for instance, in industries that are quite mature and offer little growth opportunities, such as manufacturing.

Our theory generates a number of predictions. First, the variance of career success (measured in wages and status) of a cohort entering an internal labor market is lower than the one of a cohort entering an up-or-out hierarchy. Second, juniors work harder in up-orout than in an internal labor market; while this is not necessarily so for seniors. Third, the model predicts differences in the spans of control in up-or-out and in an internal labor market: the ratio of juniors and (in the case of the internal labor market) unsuccessful seniors over successful (promoted) seniors is smaller in up-or-out than in the internal labor market.

The prediction on the span of control seems to be the most fruitful avenue to generate empirical support. ${ }^{6}$ We hence have collected some information about the top 50 economics departments in the U.S. (an up-or-out system) and in France (an internal labor market, in which tenure is given at the entry level). The results are in line with the prediction of the model: the span of control in France is more than three times higher than the one in U.S. research departments.

The next section relates our paper to the literature; Section 3 sets up the model; Section 4 presents the main results. Section 5 derives implications and presents our empirical observations. Section 6 concludes.

\footnotetext{
${ }^{6}$ Notice that a large variance in wages is also a natural feature of models in which promotion is a signal. Furthermore, it is hard to compare the effort levels of seniors empirically.
} 


\section{Related Literature}

We share a common interest with the existing papers on up-or-out contracts, but there are some notable differences, both in terms of underlying assumptions and predictions. First, Demougin and Siow (1994) and O'Flaherty and Siow (1995) are not about incentives. Rather, firms decide on either to staff all junior positions with trainees for managerial positions only, or to staff the junior positions also with people who work productively. Whether or not upor-out is optimal depends on demand. In particular, if current demand is low, but growth is high, up-or-out is optimal. We consider a steady state organization, and in our theory, juniors and seniors do the same kind of work, which seems a fair description of law firms, consulting or academia. The main interest that relates us to Demougin and Siow (1994) and O'Flaherty and Siow (1995) lies in determining the relative sizes of different hierarchical levels and, thus, the span of control of hierarchies.

The second group of papers is on incentives. Kahn and Huberman (1988) suggest a model in which firms want to incentivize agents to invest in human capital, but there is limited commitment of the firms. Output is only observable to the firm; it thus may pretend that the output is not high enough in order to save on the promised reward. This would undermine the incentive effects of the proposed reward. By announcing that anyone who does not get the reward will be fired, the firm can commit itself not to cheat, because otherwise it will lose the accumulated human capital of the worker. The model combines bilateral moral hazard with the assumption that output cannot be verified. Prendergast (1993) suggests a model in which promotions, together with wage structures that a firm can commit itself to, can solve similar problems related to unverifiability and specific human capital acquisition. The assumption of unverifiable output is also present in Waldman (1984) and (1990) and in Ghosh and Waldman (2010) in which promotion is a signal to the outside world about the productivity of a person, while output is not observable to the outside world. Waldman (1984) introduced this idea and then showed (Waldman, 1990) that the Kahn and Huberman (1988) model works in a setting with general human capital if promotion as a signal is considered. Ghosh and Waldman (2010) compare standard promotion practices 
(similar to what we call an internal labor market) with up-or-out, and show that up-or-out is optimal if firm-specific human capital is low. They also show that if the firm can commit to a wage floor, up-or-out is used when low and high-level jobs are similar.

Our paper is different from the literature, because we do not focus on the acquisition of specific human capital. In our model, promotion systems are used to differentiate the status of workers, for the purpose of generating effort incentives. Human capital is certainly an important element determining optimal promotion systems, but as our theory shows, it is not a necessary condition for an incentive theory of promotion hierarchies to exist. Our theory applies when people care about status and verifiability of output is not an issue, while the other theories apply when output cannot be verified and people have standard utility functions.

\section{Model}

We employ an overlapping generation model. At any date, the organization is staffed with members of two generations. Each person has a work life time of two periods. Juniors enter the organization and work their first period, and seniors who joined the organization in the previous period are spending the last period of their working life in the firm. It is assumed that the population of agents is constant and large so that it may be represented by a continuum. The size of the workforce employed by the firm is normalized to 2 , that is, we look at a firm in steady state.

The risk-neutral organizational designer maximizes profit:

$$
\sum_{t=0}^{+\infty} \delta^{t} \pi_{t}=\sum_{t=0}^{+\infty} \delta^{t}\left(Q_{t}-W_{t}\right)
$$

where $Q_{t}$ is total output (its price is normalized to 1 without loss of generality) and $W_{t}$ is the wage bill in period $t$. The principal's objective function is intertemporally separable with a discount factor $\delta \leq 1$. In what follows, we set $\delta=1$ which is innocuous for our purpose. 
The organizational designer uses two instruments, compensation and allocation of status. Before setting up the full program of the designer, we describe the production process, workers' preferences, and the feasible allocations of status.

\subsection{Production}

Each worker living at date $t$, junior or senior, exerts an effort $e_{t}^{i} \geq 0$ through which he contributes an amount $q_{t}^{i}$ to the firm's output. Workers are hired to do the same type of work. With probability $\mu\left(e_{t}^{i}\right), q_{t}^{i}$ is high $\left(q_{t}^{i}=q+\Delta q, \Delta q>0\right)$, and with probability $1-\mu\left(e_{t}^{i}\right)$, $q_{t}^{i}$ is low $\left(q_{t}^{i}=q\right)$. Thus, $q$ is the base-line output, and the total output at date $t, Q_{t}=\int_{0}^{2} q_{t}^{i} d i$, is random. Individual output $q_{t}^{i}$ is verifiable and its realization is independent across time. The probability of high output of agent $i, \mu\left(e_{t}^{i}\right)$, increases with $e_{t}^{i}$. More specifically we assume that

$$
\mu\left(e_{t}^{i}\right)=\min \left\{e_{t}^{i}, 1\right\}, \forall e_{t}^{i} \geq 0
$$

While output $q_{t}^{i}$ is ex-post verifiable, the effort level $e_{t}^{i}$ is not. There are two types of workers, $g$ and $b$. Type $g$ workers are more productive than type $b$ workers. The disutility of effort is

$$
\psi_{\tau}\left(e_{t}^{i}\right)=\frac{\left(e_{t}^{i}\right)^{2}}{2} a_{\tau}, \tau=g, b
$$

The larger is $a_{\tau}$, the more difficult it is for an agent to achieve a high output. ${ }^{7}$ In equilibrium the probability of success is inversely related to $a_{\tau}$. To capture the idea that $g$ workers are more productive than $b$ workers we assume that $a_{b}>a_{g}>0$.

\footnotetext{
${ }^{7}$ Equivalently, we could assume $\mu_{\tau}(e)=\min \left\{\frac{e}{a_{\tau}}, 1\right\}$ and $\psi_{\tau}(e)=\frac{e^{2}}{2}$, with similar results.
} 


\subsection{Preferences}

We assume that utilities are additively separable across periods with some discount factor (which we will set to one). Workers are protected by limited liability. In any of the periods an agent with productivity of type $\tau$, with status $s \geq 0$, income $w \geq 0$, and effort level $e \geq 0$ has the following utility function:

$$
U_{\tau}(s, w, e)=s w-\psi_{\tau}(e)
$$

Our assumption that money and status re-enforce each other requires some explanations. We posit the same utility function as Auriol and Renault (2008), which is situated between perfect substitutes and perfect complements. The indifference curves for money and status at given effort level are strictly decreasing, thus there is some substitution between status and income. This substitution is however imperfect: a superb job title does not compensate for a wage of nil, nor does a stellar wage make up for a lack of appreciation by others. The utility function also implies that the marginal rate of substitution between effort and income is decreasing in status. Put differently, for a given level of monetary incentives, an agent should be all the more willing to exert effort when she has higher status. Furthermore, the marginal rate of substitution between effort and status is decreasing in income. Thus, individuals with higher income will be willing to exert more effort in order to improve their status. Maslow's (1954) hierarchy of needs is in line with this, and Centers and Bugental (1966) find evidence employees earning higher wages care more for factors at the top of Maslow's hierarchy of needs.

These observations indicate that our assumption is a reasonable one, but direct empirical evidence on the shape of utility functions is hard to find. While some authors in the literature on status have conjectured that there are the complementarities we assume (for instance, Kosfeld and Neckermann, forthcoming), systematic evidence about the interplay between status and social recognition, and money is so far lacking in economics. A first piece of evidence from experimental economics is by Bradler and Neckermann (2011) who found that 
in a field experiment a monetary reward and a thank-you card (albeit given to everybody) increased performance to some limited extent when given in combination. Evidence on the re-enforcement of money and social recognition exists in industrial psychology. In particular, Stajkovic and Luthans (2003) carry out a meta-analysis of 72 studies with more than 13,000 subjects. They find that provided that there is performance feedback (as in our theory in which performance is common knowledge), monetary incentives and social recognition re-enforce each other, as postulated in our theory.

\subsection{Organizational design}

An organization can establish a status ranking of their workers through different means like the distribution of wages, the allocation of scarce nonmonetary resources, e.g., corner offices, or, most commonly, the hierarchical structure. Some of these attributes also provide material benefits, whereas others are purely symbolic and are valued for the social or psychological benefits they entail. We focus on these non-material sources of status, such as rank in the organization.

Any organization will be constrained in its allocation decision because increasing one individual's status comes at the expense of decreasing somebody else's status. We thus assume that status is firm-specific. To be more specific the set of feasible social status allocations is characterized as follows (the equality to 2 is a normalization).

$$
\int_{0}^{2} s_{t}^{i} d i=2, s_{t}^{i} \geq 0 \forall i, t .
$$

For each agent, the organizational designer chooses a social status allocation $s_{t}^{i}$ in (A.1), a fixed wage $w_{t}^{i}$, and a bonus $\Delta w_{t}^{i}$ in case of a high performance. Status is allocated before the workers exert effort. That is, when an agent joins the organization he is assigned to a rank somewhere in the hierarchy. The position is revised at the end of the first period based on performance.

There are two sensible promotion hierarchies in our setting. First, in an up-or-out system, 
successful former juniors are promoted and become seniors, while unsuccessful juniors have to leave. Second, in an internal labor market, again, successful juniors become seniors, but unsuccessful juniors are offered to stay in the firm and become seniors. We will show though that these unsuccessful seniors will receive a different fixed wage and status compared to their successful colleagues of the same cohort. Also, in both systems, unproductive types will stay outside of the firm.

Notice that other promotion hierarchies do not make sense because (i) a company will rationally always employ juniors; (ii) firing successful seniors would provide negative incentives.

The timing for a cohort joining the organization at date $t$ is as follows.

date 0: A new cohort of workers are offered contracts that include a junior status level, a fixed wage and an incentive wage for the first period. The firm also commits itself to a second-period contract which includes a rule for allocating status, fixed wages and incentive wages contingent on first-period performance. The firm also commits itself whether to provide an employment guarantee or to fire unsuccessful seniors and replace them by new juniors.

date 0.5: Junior workers choose an effort level given all of the above.

date 1: Outputs are observed, transfers occur and agents are promoted, retained or fired according to the terms of the contract. New juniors enter the firm.

date 1.5: Senior workers choose an effort level according to their current monetary incentive and status.

date 2: Outputs are observed, transfers occur, senior workers retire.

As the outcome $q_{t}^{i}$ which depends on effort at date $t$ is random, some agents will be successful and others not. Then an agent is characterized by its productivity $b$ or $g$, and by the fact that he is either a junior worker indexed 1 , or a senior worker with a history of high past performance, denoted $h$, or a history of low past performance, denoted $l$. 


\section{Solution of the model}

\subsection{Outside option}

In each period agents can work as individual entrepreneurs outside the firm; agents have the same kind of productivity inside and outside the firm. The only difference is that they work individually and, therefore, they cannot change the status allocation in their one-person firm. Hence, they also face different incentives. As each worker is born with one unit of status, the per-period utility of a self-employed is given as

$$
E U_{i t}=q+e_{i t} \Delta q-a_{i} \frac{e_{i t}^{2}}{2}
$$

A self-employed agent will choose the optimal effort level $\underline{e}_{i}=\frac{\Delta q}{a_{i}}$ for all $t$. The resulting expected utility is

$$
E U_{i t} \equiv \underline{U}_{i}=q+\frac{\Delta q^{2}}{2 a_{i}}
$$

Since $a_{b}>a_{g}$, reservation utility is type-dependent with $\underline{U}_{g}>\underline{U}_{b}$.

\subsection{Workers' optimal effort choices}

In the following, we assume that the firm is in steady state and consequently drop the time index. We consider first the problem of a senior worker at date 1.5. This problem is isomorphic in both promotion hierarchies, although the respective status allocations and wages differ. We can thus save on notation in terms of the type of the hierarchy considered.

Let $e_{i p}\left(s_{p}, w_{p}, \Delta w_{p}\right)$ denote the optimal effort level of senior worker of type $i \in\{g, b\}$ with status $s_{p}$ and compensation $\left(w_{p}, \Delta w_{p}\right)$, where index $p=l$ stands for low and $h$ for high past performance. The agent maximizes the following programme:

$$
E U_{i p}=s_{p}\left(e_{i p} \Delta w_{p}+w_{p}\right)-a_{i} \frac{e_{i p}^{2}}{2} .
$$


The first-order condition implies:

$$
e_{i p}^{*}=\min \left\{\frac{s_{p} \Delta w_{p}}{a_{i}}, 1\right\}, p \in\{h, l\} .
$$

We consider next the problem of a junior worker of type $i$ maximizing his expected utility, at date $t=0.5$. Agent $i$ chooses his effort $e_{i 1}$ to solve:

$$
E U_{i 1}=s_{1}\left(e_{i 1} \Delta w_{1}+w_{1}\right)+e_{i 1} \Delta U_{i}-a_{i} \frac{e_{i 1}^{2}}{2}
$$

Here $\Delta U_{i}=E U_{i h}-\underline{U}_{i}$ in an up-or-out system and $\Delta U_{i}=E U_{i h}-E U_{i l}$ for the internal labor market. The first-order condition implies:

$$
e_{i 1}^{*}=\min \left\{\frac{s_{1} \Delta w_{1}+\Delta U_{i}}{a_{i}}, 1\right\}
$$

We will restrict the analysis to the meaningful case in which there is an interior solution with respect to effort. This can be guaranteed by assuming $a_{g}$ to be high and $\Delta q$ low enough so that in equilibrium $e_{i 1}<1$ and $e_{i p} \leq 1$ :

$$
a_{g} \geq 37.5 q \text { and } \Delta q \leq 5 q
$$

\subsection{Optimal incentive contracts without status differentiation}

We here briefly describe a benchmark case in which the firm relies only on monetary incentives. Status allocation is constant and identical among workers so that $s_{i t}=1 \forall i, t$. In this classical principal/agent problem there is no benefit for the firm to postpone rewards. As the agents are risk neutral with respect to income, the optimal dynamic solution is simply the replication of the optimal static solution.

Thus, the firm maximizes the expected profit function with respect to fixed wage and bonus allocation. Assuming that there is a proportion $x$ of good and $(1-x)$ of bad agents, 
the program is as follows:

$$
\max _{w_{i}, \Delta w_{i}} \Pi=x\left(q-w_{g}+e_{g}\left(\Delta q-\Delta w_{g}\right)\right)+(1-x)\left(q-w_{b}+e_{b}\left(\Delta q-\Delta w_{b}\right)\right)
$$

subject to

$$
\begin{aligned}
& w_{i} \geq 0, \\
& e_{i}=\min \left\{\frac{\Delta w_{i}}{a_{i}}, 1\right\}, \\
& E U_{i}=w_{i}+e_{i} \Delta w_{i}-a_{i} \frac{e_{i}^{2}}{2} \geq \underline{U}_{i}=q+\frac{\Delta q^{2}}{2 a_{i}}, i \in\{g, b\} .
\end{aligned}
$$

LL stands for limited liability, IC is the incentive compatibility, and IR the individual rationality constraint. In the program above we have implicitly assumed that the firm is able to sort out workers of type $b$ and $g$ at zero cost.

We can readily show that the optimal solution derived under this assumption is implementable under the more realistic framework of asymmetric information. Under assumption A.2 we get an interior solution for the effort: $e_{i}=\frac{\Delta w_{i}}{a_{i}}$. The IR constraint then writes: $E U_{i}=w_{i}+\frac{\Delta w_{i}^{2}}{2 a_{i}} \geq q+\frac{\Delta q^{2}}{2 a_{i}}, i \in\{g, b\}$. The firm's objective function decreases with $w_{i}$ so that the IR constraints bind. Substituting $w_{i}=q+\frac{\Delta q^{2}}{2 a_{i}}-\frac{\Delta w_{i}^{2}}{2 a_{i}}$ in (8) and optimizing with respect to $\Delta w_{i}$ yields: $\Delta w_{i}=\Delta q$ so that $w_{i}=q \forall i \in\{g, b\}$. This solution is implementable under asymmetric information as workers become residual claimants of their work and the firm makes zero profit on both types of workers:

Result 1 If status is not differentiated, the profit maximizing incentive contract, $w=q$ and $\Delta w=\Delta q$, is independent of the type or seniority of workers. Both types of workers are entering the firm, and the firm makes zero profit. 


\subsection{Two types of promotion hierarchy}

In this subsection we present two propositions describing the wages in the up-or-out system, and in the internal labor market. We then investigate under what conditions either one or the other is optimal for the firm. The propositions build on one of the main results in Auriol and Renault (2008), namely that juniors receive zero wages and status (Auriol and Renault, 2008, Proposition 3). Our main contribution is to investigate the precise shapes of the promotion hierarchy, and to predict under what circumstances either of the two promotion systems is optimal. The paper also shows that a promotion hierarchy acts as a device to make less productive types stay outside of the firm (which increases profits of the firm).

In the up-or-out system, the firm maximizes expected output minus wages, subject to the ex ante participation constraint of the good worker, and the interim participation constraint of a successful worker to be satisfied. The firm also faces the status feasibility constraint (A.1) and limited liability constraints.

The following Proposition fully characterizes the optimal up-or-out system. The proof for this and the other propositions can be found in the Appendix.

Proposition 1 In an up-or-out system, unsuccessful former juniors must leave the firm, while successful juniors are promoted. The optimal up-or-out contract induces sorting, that is, only the good workers apply for jobs in the firm. Wages and status allocation are as follows: (i) junior workers receive minimum rewards and status $\left(w_{1}^{U}=0, \Delta w_{1}^{U}=0, s_{1}^{U}=0\right)$; (ii) successful seniors receive $w_{h}^{U}=\frac{2 \sqrt{a_{g} \underline{U}_{g}}}{s_{h}^{U}}-s_{h}^{U} \frac{\Delta q^{2}}{2 a_{g}}+\frac{\underline{U}_{g}}{s_{h}^{U}}, \Delta w_{h}^{U}=\Delta q, s_{h}^{U}=1+\frac{1}{2} \sqrt{\frac{a_{g}}{\underline{\underline{U}}_{g}}}$.

The up-or-out hierarchy provides strong incentives to junior workers. By bundling social and material rewards in one state of the world, large firms create prizes for their workers who are willing to take the gamble to get the prestigious and lucrative promotion. They work harder than in self employment $\left(e_{1 g}^{U}=2 \sqrt{\frac{\underline{U}_{g}}{a_{g}}}=2 \sqrt{\frac{q}{a_{g}}+\frac{\Delta q^{2}}{2 a_{g}^{2}}}>\underline{e}_{g}=\frac{\Delta q}{a_{g}}\right)$ in the hope to stay on board and receive a substantial increase in status and high wages. The principal actually loses money on the promoted seniors, but this loss is more than compensated by the surplus he extracts from the juniors. A large firm that offers an up-or-out hierarchy 
engineers promotion packages that combine social and material rewards, and, through this packaging, makes profits.

The offer of a promotion hierarchy also makes it possible to sort out at no cost the most productive workers. Indeed, in up-or-out promotion systems social and monetary rewards are not only delayed in time, as in any promotion system, but they are allocated only to successful employees. With such a structure workers with low ability are less likely to get a reward for their effort. They rather stick to self-employment. The ability to attract the most productive workers and to extract a high level of effort from them creates a competitive edge for large firms.

The program in the internal labor market has one main difference compared to the upor-out system: in the internal labor market, nobody is fired. Unsuccessful juniors stay in the firm, but the firm distinguishes status and wages of successful vs. unsuccessful seniors. The optimal internal labor market is characterized in the following proposition:

Proposition 2 In an internal labor market, all workers stay in the firm. The optimal internal labor market contract induces sorting, that is, only the good workers apply for jobs in the firm. Wages and status allocation are as follows: (i) junior workers receive minimum rewards and status $\left(w_{1}^{I}=0, \Delta w_{1}^{I}=0, s_{1}^{I}=0\right)$; (ii) successful seniors receive

$$
w_{h}^{I}=w_{l}^{I} \sqrt{\sqrt{\frac{2 a_{g}}{\underline{U}_{g}}}+1}, \Delta w_{h}^{I}=\Delta q, s_{h}^{I}=\frac{2 \sqrt{\sqrt{\frac{2 a_{g}}{\underline{U}_{g}}}+1}}{1+\sqrt{\frac{2 \underline{U}_{g}}{a_{g}}}\left(\sqrt{\sqrt{\frac{2 a_{g}}{\underline{U}_{g}}}+1}-1\right)}
$$

and (iii) unsuccessful seniors receive

$$
w_{l}^{I}=\frac{\underline{U}_{g}}{s_{l}^{I}}-\frac{s_{l}^{I} \Delta q^{2}}{2 a_{g}}, \Delta w_{l}^{I}=\Delta q, s_{l}^{I}=\frac{2}{1+\sqrt{\frac{2 \underline{U}_{g}}{a_{g}}}\left(\sqrt{\sqrt{\frac{2 a_{g}}{\underline{U}_{g}}}+1}-1\right)} .
$$

Unsuccessful seniors receive a lower status compared to their successful counterparts. In a way similar to the up-or-out contract, a firm with an internal labor market loses money on 
both types of seniors, but this loss is more than compensated by the surplus extracted from the juniors.

Both up-or-out and the internal labor market succeed in inducing sorting and in both types of promotion hierarchies, juniors only receive incentives linked to promotion. Seniors have first best incentives; they receive the entire surplus associated with a success. Comparing the profits of the firm in the two systems we can answer the question of optimality of the two systems in the next Proposition.

Proposition 3 A firm's optimal choice between up-or-out or internal labor market depends on the payoff associated to a success $\Delta q$, and the difficulty of achieving a success for the productive workers $a_{g}$ : (i) if $\Delta q$ is sufficiently large compared to $q\left(\frac{\Delta q}{q} \geq \Delta^{l} \sim 1.513\right)$,

then, up-or-out is optimal; (ii) if $\frac{\Delta q}{q}<\Delta^{l}$ and $a_{g}$ sufficiently large compared to $q\left(\frac{a_{g}}{q} \geq\right.$ $a^{l} \sim 159.36$ ), then, again up or out is optimal; (iii) otherwise, the internal labor market is optimal.

\section{Implications}

The last Proposition establishes that the up-or-out system dominates when the surplus generated by high effort is sufficiently large and whenever the difficulty of achieving a success is sufficiently large. This is in line with casual observations that up-or-out dominates in fields in which there are large sums at stake or in which people have to work very hard to succeed. Examples include law firms or consulting firms in which winning a law suit or a new, important client makes all the difference and people work both intensively and extensively, in particular when fighting for partnership status. But this also is in line with the arts, as for example in the music business where the "up" consists in a long-term contract with a publishing house, or in science where the "up" is getting tenure. As we all know, in many (but not all) countries scientists are used to be granted tenure only after six to ten years on the job, and not making tenure at a prestigious university is perceived as a substantial loss in expected status. 


\subsection{Predictions}

An applied theory like ours should generate empirical predictions allowing to test it against alternative theories and to corroborate its assumptions. We here first discuss some of these testable implications, and then present some descriptive statistics from U.S. and French economics departments, which are in line with a prediction of our theory.

A first observation relates to the wage and status profiles over time. Juniors who enter the up-or-out system have a higher variance in terms of both status and wages than in the internal labor market: successful seniors are promoted to jobs with high wages and high status, while unsuccessful seniors leave to self-employment. In the internal labor market both wage and status profiles are less steep than under up or out. Most importantly, unsuccessful seniors stay in the firm and enjoy positive status. Nonetheless, in both systems, juniors are paid minimum wages and receive no status.

A second observation builds on a comparison of effort levels of juniors. Omitting the subscript for the type of worker, because only $g$ type workers enter the firm, this is $e_{1}^{U}=$ $2 \sqrt{\frac{\underline{U}_{g}}{a_{g}}}$ in up-or-out, compared to $e_{1}^{I}=\sqrt{\frac{2 \underline{U_{g}}}{a_{g}}}$ in the internal labor market. Thus, we have $e_{1}^{I}=\frac{1}{\sqrt{2}} e_{1}^{U}$; hence juniors work harder under an up-or-out contract. This seems to be in line with casual evidence, whereby junior employees in industries that use up-or-out contracts such as consulting, law, or investment banking, are reputed to work harder than junior employees in industries that use internal labor markets.

Third, effort of seniors is $e_{h}^{U}=s_{h}^{U} \frac{\Delta q}{a_{g}}$ with up-or-out and $e_{h}^{I}=s_{h}^{I} \frac{\Delta q}{a_{g}}$ or $e_{l}^{I}=s_{l}^{I} \frac{\Delta q}{a_{g}}$ in the internal labor market. We have $1 \leq s_{l}^{I} \leq 2 \leq s_{h}^{I}$. Therefore, successful seniors work harder than unsuccessful seniors in the internal labor market. However, for the high performers of the past in the two systems, the comparison is not as clear cut. We can have $s_{h}^{U} \gtreqless s_{h}^{I}$. Therefore, seniors in the top position of a firm with an internal labor market (e.g. c-level executives in large industrial companies) may work harder than seniors in a firm that employs up-or-out contracts.

A fourth prediction applies to spans of control as implied by the two promotion systems. As juniors work harder in an up-or-out hierarchy, there are more successful seniors than 
in an internal labor market, but not everyone succeeds. Unsuccessful seniors are replaced by new juniors, while in an internal labor market, the unsuccessful seniors stay on. As a consequence, the ratio of juniors and unsuccessful seniors over successful seniors in an ILM is larger than the ratio of juniors over seniors in an up-or-out organization.

\subsection{An empirical observation in line with the model}

The last prediction can be investigated by constructing the ratio with data from U.S. and French economics departments. In the U.S., assistant professors take up to 10 years to receive tenure, usually as full professor, but in many countries in continental Europe, universities give researchers tenure at the entry level. We gathered information about the numbers of full professors, associate and assistant professors from 50 top U.S. research universities as ranked by Dusansky and Vernon (1998), as well as from the largest 50 French economics departments as ranked by Bosquet et al. (2010). ${ }^{8}$ For the U.S. system we count both assistant and associate professors as juniors, leaving aside the fact that there are some places that give tenure on the associate level. For the French system, we use the fact that researchers at universities maintain the entry level "Maitre de conférences" unless they are promoted to the rank of professor through a nation-wide competition. Similarly, researchers in other institution such as the CNRS, the national science center, can either stay on the entry level ("chargé de recherche"), or be promoted ("directeur de recherche").

We can thus compare the ratio of assistant and associate professors over full professors in the U.S. (Table 1), with the ratio of the so-called Rank B (juniors and non-promoted seniors) to Rank A (senior researchers and professors) in France (Table 2). Notice that U.S. universities are ranked in alphabetical order, while French ones by rank, for reasons explained below.

$<$ Tables 1, 2 about here. $>$

\footnotetext{
${ }^{8}$ We are grateful to Pierre-Philippe Combes who provided us with the data from Bosquet et al. (2010) and helped us in using the data. U.S. data are hand-collected from the departments' websites.
} 
Just as predicted by the model, the U.S. ratio is much smaller (0.73) than the French ratio (2.8), a difference that a Mann-Whitney test identifies as highly significant $(p<0.001)$. This supporting evidence fits the different missions of U.S. and French universities, which are quite similar to what our theory predicts about the optimality of up-or-out vs. internal labor market. U.S. research universities are largely oriented towards producing research output for the international market. French universities have a mixed set of objectives. Traditionally, there has been a division of labor between the CNRS, and universities, which are supposed to be more teaching-oriented. While some universities have developed remarkable scientific capacity, the research output of most universities is quite low compared to the U.S.. The goals and production technology of French universities and the associated expected payoffs are hence different from the ones in U.S. research universities. While in the U.S. it is relatively hard to achieve a success, such as for instance, publications in the American Economic Review, Econometrica or Science, it is easier to publish in a French-speaking journal or provide undergraduates with reasonable teaching. Similarly, the payoffs of achieving the respective success are smaller in France than in the U.S..

We find another piece of evidence that is in line with our theory (and the reason for arranging french universities by rank). The French university system is currently undergoing a transformation that is quite similar to many other European countries. In the course of this transformation which involves increased autonomy, and funding related to research performance, the difference between the stronger and weaker economics departments is increasing. Only few of the French departments can be meaningfully compared to their U.S. counterparts in terms of research output. However, a clear picture emerges: while the top 20 departments have a junior/senior ratio of 1.6, the following 30 departments have a ratio of 3.7. This means that the better ranked the departments in terms of scientific output, and hence the closer the departments in terms of their mission to the ideal of scientific excellence, the less substantial is the difference of the ratio to the U.S. departments.

We would like to point out that these figures should not be overinterpreted as a test of the model, because a number of institutional specificities make it impossible to exclude other 
factors. In particular, in our model, the firm is in steady state, and this is definitely not the case in France. We nonetheless see these observations as support for our theory.

\section{Concluding remarks}

We have suggested a simple dynamic agency model in which firms can make profits by offering promotion opportunities to successful juniors. The hierarchies differ with respect to the treatment of unsuccessful juniors. In up-or-out, these unsuccessful juniors must go, while in the internal labor market they can stay. We have shown that these promotion hierarchies both succeed in inducing sorting: only the more productive workers want to work in these organizations. We have also derived some testable implications, and find some corroborative data from the French and the U.S. university system. We have shown that up-or-out is the profit maximizing promotion hierarchy for very high payoffs of successful work of juniors and when the task is causing high costs of effort, while otherwise internal labor markets dominate. 


\section{References}

Auriol, Emmanuelle and Régis Renault (2001), "Incentive Hierarchies", Annales d'Economie et de Statstique, 63-64, pp. 261-82

Auriol, Emmanuelle and Régis Renault (2008), "Status and Incentives", RAND Journal of Economics, 39(1), pp. 305-326

Baker, George, Michael Gibbs and Bengt Holmström (1994), "The Internal Economics of the Firm", Quarterly Journal of Economics, 109(4), pp. 881-919

Barnard, Chester (1938): The Functions of the Executive, Harvard University Press, Cambridge (Mass.)

Besley, Tim and Maitreesh Ghatak (2008), "Status Incentives", American Economic Review (Papers and Proceedings), 98(2), pp. 206-211

Bosquet, Clément, Pierre-Philippe Combes and Laurent Linnemer (2010), "La publication d'articles de recherche en économie en France en 2008: Disparités actuelles et évolutions depuis 1998", Rapport pour la Direction Générale de la Recherche et de l'Innovation (DGRI) du Ministère de l'Enseignement Supérieur et de la Recherche

Bradler, Christiane and Susanne Neckermann (2011), "Motivational Production Function - A Field Experiment", paper presented in the workshop on "Field Experiments in Organizational and Labor Economics", Frankfurt.

Centers, Richard and Daphne E. Bugental (1966), "Extrinsic and Intrinsic Job Satisfaction Among Different Segments of Work Population", Journal of Applied Psychology, 50(3), pp. $193-197$

Demougin, Dominique and Aloysius Siow (1994), "Careers in Ongoing Organizations", American Economic Review, 84(5), pp. 1261-1277 
Doeringer, Peter and Michael Piore (1971), Internal Labor markets and Manpower Analysis, Heath Lexington Books, D.C. Heath and Company Lexington, Massachusetts

Drucker, Peter F. (1954), The Practice of Management, Harper \& Row, New York

Dusansky, Richard and Clayton J. Vernon (1998), "Rankings of U.S. Economics Departments", Journal of Economic Perspectives, 12(1), pp. 157-170

Frank, Robert (1985), Choosing the Right Pond: Human Behavior and the Quest for Status, Oxford University Press

Ghosh, Suman and Michael Waldman (2010), "Standard Promotion Practices versus Upor-Out Contracts", RAND Journal of Economics, 41(2), pp. 301-325

Gibbons, Robert and Michael Waldman (1999), "Careers in Organizations: Theory and Evidence", Handbook of Labor Economics, Vol. 3B, 2373-2438, Elsevier

Huberman, Bernardo A., Christoph H. Loch and Ayse Önçüler (2004), "Status As a Valued Resource", Social Psychology Quarterly, 67(1), pp. 103-114

Kahn, Charles and Gur Huberman (1988), "Two-sided Uncertainty and "Up-or-Out" Contracts", Journal of Labor Economics, 6(4), pp. 423-44

Kosfeld, Michael and Susanne Neckermann (forthcoming), "Getting More Work for Nothing? Symbolic Awards and Worker Performance", American Economic Journal: Microeconomics

Maslow, Abraham (1954), "Motivation and Personality", New York, Harper and Row

Moldovanu, Benny, Aner Sela and Xianwen Shi (2007), "Contests for Status", Journal of Political Economy, 115(2), 338-363

O'Flaherty, Brendan and Aloysius Siow (1995), "Up-or-Out Rules in the Market for Lawyers", Journal of Labor Economics, 13(4), pp. 709-735 
Prendergast, Canice (1993), "The Role of Promotion in Inducing Specific Human Capital Acquisition", Quarterly Journal of Economics, 108(2), pp. 523-34

Stajkovic, Alexander and Fred Luthans (2003), "Behavioral Management and Task Performance in Organizations: Conceptual Background, Meta-Analysis, and Test of Alternative Models, Personnel Psychology, 56(1), pp. 155-194

von Siemens, Ferdinand A. (2010), "Heterogeneous Social Preferences, Screening, and Employment Contracts", Oxford Economic Papers, 63(3), 499-522

Waldman, Michael (1984), "Job Assignments, Signalling and Efficiency", Rand Journal of Economics, 15(2), pp. 255-267

Waldman, Michael (1990), "Up-Or-Out Contracts: A Signaling Perspective", Journal of Labor Economics, 8(2), pp. 230-250

Waldman, Michael (2009), "Theory and Evidence in Internal Labor Markets", forthcoming in Robert Gibbons and John Roberts (eds.), Handbook of Organizational Economics. 


\section{Proof of Proposition 1}

We take Proposition 3 from Auriol and Renault (2008) as given:

Proposition 3 (Auriol and Renault, 2008): Under Assumptions 1, 2, and 3, in any steady state of a profit-maximizing solution, we have:

$$
\begin{aligned}
\Delta w_{1} & =w_{1}=s_{1}=0 . \\
s_{h} & >s_{l} \\
w_{h} & \geq w_{l} \text { and } \Delta w_{h} \geq \Delta w_{l}
\end{aligned}
$$

where at least one of the inequalities in (13) is strict.

Thus, juniors receive minimal wages and status. If A.2 holds, $a_{g}$ is such that in equilibrium $e_{g 1}^{U}<1$ (i.e., $\Delta U_{g}<a_{g}$ ). The following Lemma establishes that $e_{g h}^{U}=\frac{s_{h}^{U} \Delta w_{h}^{U}}{a_{g}} \leq 1$.

Lemma 1 Without loss of generality at the optimum: $\Delta s_{h}^{U} w_{h}^{U} \leq a_{g}$.

If $\Delta w_{h}^{U}>\frac{a_{g}}{s_{h}^{U}}$, then $e_{g h}^{U}=1$. Let $\epsilon=\Delta w_{h}^{U}-\frac{a_{g}}{s_{h}^{U}}$ and $\Delta w_{h}^{U \prime}=\Delta w_{h}^{U}-\epsilon$, and $w_{h}^{U \prime}=w_{h}^{U}+\epsilon$. This implies $e_{g h}^{U \prime}=e_{g h}^{U}=1, E U_{h}=E U_{h}^{\prime}$, and $E \Pi=E \Pi^{\prime}$. QED

By Lemma $1 e_{i h}^{U}=\frac{s_{h}^{U} \Delta w_{h}^{U}}{a_{i}}$, and by assumption $e_{i 1}^{U}=\frac{\Delta U_{i}}{a_{i}}<1$. This implies that $E U_{i h}=$ $s_{h}^{U}\left(e_{i h}^{U} \Delta w_{h}^{U}+w_{h}^{U}\right)-a_{i} \frac{e_{i h}^{U 2}}{2}=\frac{\left(s_{h}^{U} \Delta w_{h}^{U}\right)^{2}}{2 a_{i}}+s_{h}^{U} w_{h}^{U}$ and $E U_{i 1}=e_{i 1}^{U} \Delta U_{i}-a_{i} \frac{e_{1}^{U 2}}{2}=\frac{\Delta U_{i}^{2}}{2 a_{i}}$ with $\Delta U_{i}=$ $E U_{i h}-\underline{U}_{i}=\frac{\left(s_{h}^{U} \Delta w_{h}^{U}\right)^{2}}{2 a_{i}}+s_{h}^{U} w_{h}^{U}-\underline{U}_{i}$. Then $\frac{\partial \Delta U_{i}}{\partial w_{h}^{U}}=s_{h}^{U} ; \frac{\partial \Delta U_{i}}{\partial \Delta w_{h}^{U}}=\frac{s_{h}^{2} \Delta w_{h}^{U}}{a_{i}} ; \frac{\partial \Delta U_{i}}{\partial s_{h}^{U}}=\frac{s_{h}^{U} \Delta w_{h}^{U 2}}{a_{i}}+w_{h}^{U} ;$ and $\left(\frac{2 \Delta U_{g}}{a_{g}+\Delta U_{g}}\right)^{\prime}=\frac{2 a_{g} \Delta U_{g}^{\prime}}{\left(a_{g}+\Delta U_{g}\right)^{2}}$.

The firm maximizes expected profits:

$$
\begin{aligned}
\max E \Pi & =\frac{2}{1+e_{g 1}^{U}}\left(e_{g 1}^{U} \Delta q+q\right)+\frac{2 e_{g 1}^{U}}{1+e_{g 1}^{U}}\left(e_{g h}^{U}\left(\Delta q-\Delta w_{h}^{U}\right)-w_{h}^{U}+q\right) \\
& =2\left(\frac{e_{g 1}^{U}}{1+e_{g 1}^{U}}\left(\Delta q+e_{g h}^{U}\left(\Delta q-\Delta w_{h}^{U}\right)-w_{h}^{U}\right)+q\right)
\end{aligned}
$$




$$
\begin{aligned}
\text { s.t. } E U_{g h} & \geq \underline{U}_{g}\left(I R_{g h}\right) \\
E U_{g 1}=\frac{\Delta U_{g}^{2}}{2 a_{g}} & \geq 2 \underline{U}_{g}\left(I R_{g 1}\right) \\
E U_{b 1}=\frac{\Delta U_{b}^{2}}{2 a_{b}} & <2 \underline{U}_{b}\left(I R_{b 1}\right) \\
\frac{2 e_{g 1}^{U}}{1+e_{g 1}^{U}} s_{h}^{U} & =2 \text { (status feasibility) } \\
w_{h}^{U} & \geq 0 \\
s_{h}^{U} \Delta w_{h}^{U} & \leq a_{g} \\
e_{g 1}^{U} & =\frac{\Delta U_{g}}{a_{g}} ; e_{g h}^{U}=\frac{s_{h}^{U} \Delta w_{h}^{U}}{a_{g}}
\end{aligned}
$$

The Lagrangian is:

$$
\begin{aligned}
& L=\frac{2 \Delta U_{g}}{a_{g}+\Delta U_{g}}\left(\Delta q+\frac{s_{h}^{U} \Delta w_{h}^{U}}{a_{g}}\left(\Delta q-\Delta w_{h}^{U}\right)-w_{h}^{U}\right)+2 q+\alpha\left(\frac{\left(s_{h}^{U} \Delta w_{h}^{U}\right)^{2}}{2 a_{g}}+s_{h}^{U} w_{h}^{U}-\underline{U}_{g}\right) \\
& +\beta_{g}\left(\frac{\Delta U_{g}^{2}}{2 a_{g}}-2 \underline{U}_{g}\right)+\beta_{b}\left(2 \underline{U}_{b}-\frac{\Delta U_{b}^{2}}{2 a_{b}}\right)+\gamma\left(2-\frac{2 \Delta U_{g}}{a_{g}+\Delta U_{g}} s_{h}^{U}\right)+\lambda_{h} w_{h}^{U}+\epsilon_{h}\left(a_{g}-s_{h}^{U} \Delta w_{h}^{U}\right)
\end{aligned}
$$

It is useful to define

$$
\begin{aligned}
D & :=\Delta q+\frac{s_{h}^{U} \Delta w_{h}^{U}}{a_{g}}\left(\Delta q-\Delta w_{h}^{U}\right)-w_{h}^{U}-\gamma s_{h}^{U} \\
B & :=\frac{2 D a_{g}}{\left(a_{g}+\Delta U_{g}\right)^{2}}+\beta_{g} \frac{\Delta U_{g}}{a_{g}}+\alpha .
\end{aligned}
$$

From the Lagrangian, we derive the following conditions:

$$
\begin{aligned}
& \alpha \geq 0 ; \beta_{g} \geq 0 ; \beta_{b} \geq 0 ; \gamma \geq 0 ; \lambda_{h} \geq 0 ; \epsilon_{h} \geq 0 . \\
& \alpha\left(E U_{g h}-\underline{U}_{g}\right)=0 \\
& \beta_{g}\left(\frac{\Delta U_{g}^{2}}{2 a_{g}}-2 \underline{U}_{g}\right)=0 \\
& \beta_{b}\left(2 \underline{U}_{b}-\frac{\Delta U_{b}^{2}}{2 a_{b}}\right)=0
\end{aligned}
$$




$$
\begin{aligned}
& \gamma\left(2-\frac{2 \Delta U_{g}}{a_{g}+\Delta U_{g}} s_{h}^{U}\right)=0 \\
& \lambda_{h} w_{h}^{U}=0 \\
& \epsilon_{h}\left(a_{g}-s_{h}^{U} \Delta w_{h}^{U}\right)=0 \\
& \frac{\partial L}{\partial \Delta w_{h}^{U}}=\frac{s_{h}^{U} \Delta w_{h}^{U}}{a_{g}} B-\frac{s_{h}^{U} \Delta w_{h}^{U}}{a_{b}^{2}} \beta_{b} \Delta U_{b}+\frac{2 \Delta U_{g}}{\left(a_{g}+\Delta U_{g}\right) a_{g}}\left(\Delta q-2 \Delta w_{h}^{U}\right)-\epsilon_{h}=0 \\
& \frac{\partial L}{\partial s_{h}^{U}}=\left(\frac{s_{h}^{U} \Delta w_{h}^{U}}{a_{g}}+\frac{w_{h}^{U}}{\Delta w_{h}^{U}}\right) B-\left(\frac{s_{h}^{U} \Delta w_{h}^{U}}{a_{b}}+\frac{w_{h}^{U}}{\Delta w_{h}^{U}}\right) \beta_{b} \frac{\Delta U_{b}}{a_{b}}+ \\
& \frac{\partial L}{a_{g}\left(a_{g}+\Delta U_{g}\right)}\left(\Delta q-\Delta w_{h}^{U}\right)-\gamma \frac{2 \Delta U_{g}}{\Delta w_{h}^{U}\left(a_{g}+\Delta U_{g}\right)}-\epsilon_{h}=0 \\
& w_{h}^{U}=s_{h}^{U}\left(B-\beta_{b} \frac{\Delta U_{b}}{a_{b}}\right)-\frac{2 \Delta U_{g}}{a_{g}+\Delta U_{g}}+\lambda_{h}=0
\end{aligned}
$$

To derive the optimal up-or-out contract as stated in Proposition 1, we assume that equilibrium satisfies the following two conditions:

$$
\begin{aligned}
& w_{h}^{U}>0 \text { which implies } \lambda_{h}=0 \\
& \beta_{b}=0 \text { which implies } E U_{b 1}<2 \underline{U}_{b} .
\end{aligned}
$$

After deriving the optimal contract, we will check that (26) is fulfilled in equilibrium, and that (27) is implied by (26).

The following preliminary result is helpful:

Lemma 2 When at the optimum $w_{h}^{U}>0$, then $\Delta w_{h}^{U}=\Delta q$.

Assume that at the optimum $\Delta w_{h}^{U}$ is such that $\Delta w_{h}^{U}<\Delta q$ while $w_{h}^{U}>0$. Let $\epsilon>0$ and $\Delta \epsilon>0$ be such that $w_{h}^{U \prime}=w_{h}^{U}-\epsilon \geq 0$ and $\Delta w_{h}^{U \prime}=\Delta w_{h}^{U}+\Delta \epsilon \leq \Delta q$ with $E U_{g h}=\frac{\left(s_{h}^{U} \Delta w_{h}^{U}\right)^{2}}{2 a_{g}}+$ $s_{h}^{U} w_{h}^{U}=E U_{g h}^{\prime}=\frac{\left(s_{h}^{U} \Delta w_{h}^{U \prime}\right)^{2}}{2 a_{g}}+s_{h}^{U} w_{h}^{U \prime}$. Solving this equation yields $\epsilon=\frac{s_{h}^{U}}{2 a_{g}} \Delta \epsilon\left(2 \Delta w_{h}^{U}+\Delta \epsilon\right)$. By construction, the expected utility of a $g h$ worker is unchanged. However the principal's profit changes: she pays $\Delta \epsilon$ more with probability $e_{g h}^{U \prime}=\frac{\left(\Delta w_{h}^{U}+\Delta \epsilon\right) s_{h}^{U}}{a_{g}}$, but economizes $\epsilon$. Her 
profit thus rises by the amount: $\Delta \pi=e_{g h}^{U \prime}\left(\Delta q-\Delta w_{h}^{U \prime}\right)-w_{h}^{U \prime}-\left(e_{g h}^{U}\left(\Delta q-\Delta w_{h}^{U}\right)-w_{h}^{U}\right)$. Substituting for the new value of effort and wages, we obtain: $\Delta \pi=\frac{\left(\Delta w_{h}^{U}+\Delta \epsilon\right) s_{h}^{U}}{a_{g}}(\Delta q-$ $\left.\Delta w_{h}^{U}-\Delta \epsilon\right)+\epsilon-\frac{\Delta w_{h}^{U} s_{h}^{U}}{a_{g}}\left(\Delta q-\Delta w_{h}^{U}\right)$. This yields: $\Delta \pi=\epsilon+\frac{\Delta \epsilon s_{h}^{U}}{a_{g}}\left(\Delta q-2 \Delta w_{h}^{U}-\Delta \epsilon\right)=$ $\frac{s_{h}^{U} \Delta \epsilon}{a_{g}}\left(\Delta w_{h}^{U}+0.5 \Delta \epsilon\right)+\frac{\Delta \epsilon s_{h}^{U}}{a_{g}}\left(\Delta q-2 \Delta w_{h}^{U}-\Delta \epsilon\right)$. Since by construction, $\Delta w_{h}^{U \prime}=\Delta w_{h}^{U}+\Delta \epsilon \leq \Delta q$, then $\Delta \pi=\frac{s_{h}^{U} \Delta \epsilon}{a_{q}}\left(\Delta q-\Delta w_{h}^{U}-0.5 \Delta \epsilon\right)>0 . \mathrm{QED}$

From $(25),(26)$, and $(27)$, we have $s_{h}^{U}=\frac{2 \Delta U_{g}}{B\left(a_{g}+\Delta U_{g}\right)}$. Substituting this expression in equation (23) and applying (27) we get $\frac{2 \Delta U_{g}}{\left(a_{g}+\Delta U_{g}\right) a_{g}}\left(\Delta q-\Delta w_{h}^{U}\right)=\epsilon_{h}$. Lemma 2 and (26) then imply that $\epsilon_{h}=0$. Substituting $\epsilon_{h}=0$ and $\beta_{b}=0$ from (27) in (21) and applying $\Delta w_{h}^{U}=\Delta q$ yields $\gamma=\left(\frac{s_{h}^{U} \Delta q}{a_{g}}+\frac{w_{h}^{U}}{\Delta q}\right) \frac{\left(a_{g}+\Delta U_{g}\right) B}{2 \Delta U_{g}} \Delta q$. Finally substituting $s_{h}^{U}=\frac{2 \Delta U_{g}}{B\left(a_{g}+\Delta U_{g}\right)}$ into this expression yields $\gamma=\frac{\Delta q^{2}}{a_{g}}+\frac{w_{h}^{U}}{s_{h}^{U}}>0$. This implies in (20) that

$$
s_{h}^{U}=\frac{a_{g}+\Delta U_{g}}{\Delta U_{g}} .
$$

Substituting $\Delta U_{g}=\frac{\left(s_{h}^{U} \Delta q\right)^{2}}{2 a_{g}}+s_{h}^{U} w_{h}^{U}-\underline{U}_{g}$ in equation (28) yields

$$
w_{h}^{U}=\frac{a_{g}}{\left(s_{h}^{U}-1\right) s_{h}^{U}}-s_{h}^{U} \frac{\Delta q^{2}}{2 a_{g}}+\frac{\underline{U}_{g}}{s_{h}^{U}} .
$$

We now proceed to show that $\beta_{g}>0$. Substituting for $B$ in $(20)$, using the fact that $\epsilon_{h}, \beta_{b}$ $=0$, and substituting for $\Delta w_{h}^{U}=\Delta q$ yields $s_{h}^{U}\left(\frac{2 D a_{g}}{\left(a_{g}+\Delta U_{g}\right)^{2}}+\beta_{g} \frac{\Delta U_{g}}{a_{g}}+\alpha\right)=\frac{2}{s_{h}^{U}}$. Substituting for $D$ and rearranging yields: $\beta_{g} \frac{\Delta U_{g}}{a_{g}}+\alpha=\frac{2}{s_{h}^{U}}\left(1-\frac{a_{g}}{a_{g}+\Delta U_{g}}\left(\frac{\Delta q s_{h}^{U}}{\Delta U_{g}}-2-2 \frac{\left(s_{h}^{U}-1\right)}{a_{g}} \underline{U}_{g}\right)\right)$. We have $\beta_{g} \frac{\Delta U_{g}}{a_{g}}+\alpha>0$, if $1>\frac{a_{g}}{a_{g}+\Delta U_{g}}\left(\frac{s_{h}^{U} \Delta q}{\Delta U_{g}}-2-2 \frac{\left(s_{h}^{U}-1\right)}{a_{g}} \underline{U}_{g}\right)$ or $3-\frac{2}{s_{h}^{U}}+\frac{2}{s_{h}^{U}} \frac{\left(s_{h}^{U}-1\right)^{2}}{a_{g}} \underline{U}_{g}>$ $\frac{\left(s_{h}^{U}-1\right)^{2} \Delta q}{a_{g}}$. From (28) together with $e_{g 1}^{U}<1$, we know $s_{h}^{U} \geq 2$. A sufficient condition is thus $2 a_{g}>\left(s_{h}^{U}-1\right)^{2} \Delta q$, or by substituting $s_{h}^{U}$ we have $\frac{\Delta U_{g}^{2}}{2 a_{g}}>\frac{\Delta q}{4}$. Given the individual rationality constraint $\left(I R_{g 1}\right)$, this is fulfilled for $\frac{\Delta q}{4}<2 \underline{U}_{g}$. A sufficient condition is $\Delta q<8 q$ which is always fulfilled under A.2.

Now, $\beta_{g} \frac{\Delta U_{g}}{a_{g}}+\alpha>0$ implies $\beta_{g}>0$ and $\alpha=0$. Assume, to the contrary, $\alpha>0$. From (17) we have $E U_{g h}=\underline{U}_{g}$ and thus $\Delta U_{g}=0$. Then, the individual rationality constraint 
$\left(I R_{g 1}\right)$ with $\frac{\Delta U_{g}^{2}}{2 a_{g}} \geq 2 \underline{U}_{g}$ cannot be fulfilled. Given that $\alpha=0$, we must have $\beta_{g}>0$. Hence, $\frac{\Delta U_{g}^{2}}{2 a_{g}}=2 \underline{U}_{g}$ or $\Delta U_{g}=2 \sqrt{a_{g} \underline{U}_{g}}$. We therefore have in (28) $s_{h}^{U}=1+\frac{1}{2} \sqrt{\frac{a_{g}}{\underline{U}_{g}}}>1$. Substituting this value in (29) together with Lemma (2) yields the three conditions of Proposition 1.

It remains to be shown that profit is positive for the firm given these specifications. We have $\pi^{U}=\frac{2 e_{g 1}^{U}}{1+e_{g 1}^{U}}\left(\Delta q-w_{h}^{U}\right)+2 q$. Substituting for $s_{h}=\frac{e_{g 1}^{U}}{1+e_{g 1}^{U}}$, profit is positive if $\Delta q\left(1+e_{g 1}^{U}\right)-e_{g 1}^{U 2} a_{g}+\frac{\left(2 e_{g 1}^{U}+1\right)}{e_{g 1}^{U}} \frac{\Delta q^{2}}{2 a_{g}}+\frac{1+2 e_{g 1}^{U}}{e_{g 1}^{U}} q>0$. A sufficient condition is $\frac{\Delta q}{q}\left(1+e_{g 1}^{U}\right)-$ $e_{g 1}^{U 2} \frac{a_{g}}{q}+\frac{1+2 e_{g 1}^{U}}{e_{g 1}^{U}}>0$. Let $a=\frac{a_{g}}{q}$ and $\Delta=\frac{\Delta q}{q}$. Then, A.2 becomes $a \geq 37.5$ and $\Delta \leq 5$. Then, $e_{g 1}^{U}=\frac{\sqrt{2}}{a} \sqrt{2 a+\Delta^{2}} \in\left(0, \frac{10 \sqrt{2}}{37.5}\right]$. Thus, profit is positive if $u(a, \Delta)=\Delta\left(1+e_{g 1}^{U}(a, \Delta)\right)-$ $e_{g 1}^{U 2}(a, \Delta) a+\frac{1+2 e_{g 1}^{U}(a, \Delta)}{e_{g 1}^{U}(a, \Delta)}>0$. As both $\frac{\partial u(a, \Delta)}{\partial a}, \frac{\partial u(a, \Delta)}{\partial \Delta}>0$, it suffices to show that $u(a, \Delta)$ is positive for the lowest values $a$ and $\Delta$. We have $u(37.5,0) \sim 1.06$.

Finally, we need to check that the solution satisfies (26), and (27), and $e_{g 1}^{U}<1, e_{g h}^{U} \leq 1$.

We start with (26): $w_{h}^{U}=\frac{a_{g}}{\left(s_{h}^{U}-1\right) s_{h}^{U}}-s_{h}^{U} \frac{\Delta q^{2}}{2 a_{g}}+\frac{\underline{U}_{g}}{s_{h}^{U}}>0$. Substituting for $s_{h}^{U}$ and $\underline{U}_{g}$ we obtain a sufficient condition for this to be fulfilled: $2 \sqrt{\sqrt{\left(q a_{g}+\frac{\Delta q^{2}}{2}\right)}}>\frac{\Delta q}{\sqrt{a_{g}}}+\frac{\Delta q}{2} \sqrt{\frac{1}{q}}$. The LHS is increasing in $a_{g}$ and the RHS decreasing. Given A.2, we can thus set $a_{g}=37.5 q$. For $\frac{\Delta q}{q}<5$ (by A.2), the sufficient condition is fulfilled.

Second, we check $e_{g 1}^{U}<1$. This is equivalent to $\frac{s_{h}^{U 2} \Delta q^{2}}{2 a_{g}}+s_{h}^{U} w_{h}^{U}-\underline{U}_{g}<a_{g}$. Substituting (29) for $s_{h}^{U} w_{h}^{U}$, yields the condition $s_{h}^{U}>2$. This is equivalent to $a_{g}^{2}-4 a_{g} q-2 \Delta q^{2}>0$ or $a_{g}>2 q\left(1+\sqrt{1+\frac{\Delta q^{2}}{2 q^{2}}}\right)$. According to A.2, $a_{g} \geq 37.5 q$. Thus we have to show $37.5 q>$ $2 q\left(1+\sqrt{1+\frac{\Delta q^{2}}{2 q^{2}}}\right)$. This is equivalent to $\Delta q<\sqrt{2\left(\left(\frac{37.5}{2}-1\right)^{2}-1\right)} q \approx 25 q$ and fulfilled given A.2.

Third, we turn to (27). $E U_{b 1}<2 \underline{U}_{b}$ is equivalent to $s_{h}^{U 2} \Delta q^{2}\left(\frac{1}{a_{g}}-\frac{1}{a_{b}}\right)>2\left(\underline{U}_{g}-\underline{U}_{b}\right)-$ $4\left(\sqrt{\underline{U}_{b} a_{b}}-\sqrt{\underline{U}_{g} a_{g}}\right)$. Inserting the outside option values $\underline{U}_{i}=q+\frac{\Delta q^{2}}{2 a_{i}}$ we get $s_{h}^{U 2}\left(\frac{1}{a_{g}}-\frac{1}{a_{b}}\right)>$ $\left(\frac{1}{a_{g}}-\frac{1}{a_{b}}\right)-\frac{4}{\Delta q^{2}}\left(\sqrt{a_{b} q+\frac{\Delta q^{2}}{2}}-\sqrt{a_{g} q+\frac{\Delta q^{2}}{2}}\right)$. The second term on the RHS is negative since $a_{b}>a_{g}$. Thus, a sufficient condition is $s_{h}^{U 2}\left(\frac{1}{a_{g}}-\frac{1}{a_{b}}\right)>\left(\frac{1}{a_{g}}-\frac{1}{a_{b}}\right)$, which is always fulfilled since $s_{h}^{U}>2$. Thus, a low-ability worker would never like to enter the firm.

We finish with $e_{g h}^{U} \leq 1$ which is equivalent to $a_{g} \geq s_{h}^{U} \Delta q$. Substituting for $s_{h}^{U}$, one can check that the inequality is equivalent to $a_{g}^{2}-4 a_{g} \Delta q+2 \Delta q^{2}+a_{g}^{2} \frac{2 a_{g} q}{\Delta q^{2}+2 a_{g} q} \geq 0$. Neglecting 
the last term, a sufficient condition for this inequality to hold is $a_{g} \geq(2+\sqrt{2}) \Delta q$. Given assumption A.2 we have $a_{g} \geq 37.5 q$ and thus have to show $37.5 q \geq(2+\sqrt{2}) \Delta q$. This is fulfilled given that $\frac{\Delta q}{q}<5$ by A.2. QED 


\section{Proof of Proposition 2}

The proof is closely related to Proposition 3 in Auriol and Renault (2001), but we here consider two types of agents and identify a separating equilibrium with shutdown of the less productive type $\left(I R_{b 1}\right)$.

Let $\Delta U_{i}=E U_{i h}-E U_{i l}$. The principal is maximizing expected profits:

$$
\begin{aligned}
& \max E \Pi=e_{g 1}^{I}\left(\Delta q+e_{g h}^{I}\left(\Delta q-\Delta w_{h}^{I}\right)-w_{h}^{I}\right)+\left(1-e_{g 1}^{I}\right)\left(e_{g l}^{I}\left(\Delta q-\Delta w_{l}^{I}\right)-w_{l}^{I}\right)+2 q \\
& \text { s.t.E} U_{g l} \geq \underline{U}_{g}\left(I R_{g h}\right) \\
& E U_{g 1}=\frac{\Delta U_{g}^{2}}{2 a_{g}}+E U_{g l} \geq 2 \underline{U}_{g}\left(I R_{g 1}\right) \\
& E U_{b 1}=\frac{\Delta U_{b}^{2}}{2 a_{b}}+E U_{b l}<2 \underline{U}_{b}\left(I R_{b 1}\right) \\
& e_{g 1}^{I} s_{h}^{I}+\left(1-e_{g 1}^{I}\right) s_{l}^{I}=2(\text { status feasibility }) \\
& w_{h}^{I} \geq 0 ; w_{l}^{I} \geq 0 \\
& s_{h}^{I} \Delta w_{h}^{I} \leq a_{g} ; s_{l}^{I} \Delta w_{l}^{I} \leq a_{g} \\
& e_{g 1}^{I}=\frac{\Delta U_{g}}{a_{g}} ; e_{g p}^{I}=\frac{\Delta w_{p}^{I} s_{p}^{I}}{a_{g}} \text { for } p=l, h
\end{aligned}
$$

The Lagrangian is:

$$
\begin{aligned}
L & =\frac{\Delta U_{g}}{a_{g}}\left(\Delta q+\frac{s_{h}^{I} \Delta w_{h}^{I}}{a_{g}}\left(\Delta q-\Delta w_{h}^{I}\right)-w_{h}^{I}\right)+\left(1-\frac{\Delta U_{g}}{a_{g}}\right)\left(\frac{s_{l}^{I} \Delta w_{l}^{I}}{a_{g}}\left(\Delta q-\Delta w_{l}^{I}\right)-w_{l}^{I}\right)+2 q \\
& +\alpha\left(\frac{\left(s_{l}^{I} \Delta w_{l}^{I}\right)^{2}}{2 a_{g}}+s_{l}^{I} w_{l}^{I}-\underline{U}_{g}\right)+\beta_{g}\left(\frac{\Delta U_{g}^{2}}{2 a_{g}}+E U_{g l}-2 \underline{U}_{g}\right)+\beta_{b}\left(2 \underline{U}_{b}-\frac{\Delta U_{b}^{2}}{2 a_{b}}-E U_{b l}\right) \\
& +\gamma\left(2-\frac{\Delta U_{g}}{a_{g}} s_{h}^{I}-\left(1-\frac{\Delta U_{g}}{a_{g}}\right) s_{l}^{I}\right)+\lambda_{l} w_{l}^{I}+\lambda_{h} w_{h}^{I}+\epsilon_{h}\left(a_{g}-\Delta w_{h}^{I} s_{h}^{I}\right)+\epsilon_{l}\left(a_{g}-\Delta w_{l}^{I} s_{l}^{I}\right)
\end{aligned}
$$

It is useful to define

$$
G:=\Delta q+\frac{s_{h}^{I} \Delta w_{h}^{I}}{a_{g}}\left(\Delta q-\Delta w_{h}^{I}\right)-w_{h}^{I}-\frac{s_{l}^{I} \Delta w_{l}^{I}}{a_{g}}\left(\Delta q-\Delta w_{l}^{I}\right)+w_{l}^{I}+\frac{\beta_{g}}{2} \Delta U_{g}-\gamma\left(s_{h}^{I}-s_{l}^{I}\right)
$$


From the Lagrangian, we derive the following conditions:

$$
\begin{aligned}
\alpha \geq 0 ; \beta_{g} \geq 0 ; \beta_{b} \geq 0 ; \gamma \geq 0 ; \lambda_{l} \geq 0 ; \lambda_{h} \geq 0 ; \epsilon_{l} \geq 0 ; \epsilon_{h} \geq 0 & \\
\alpha\left(E U_{g l}-\underline{U}_{g}\right) & =0 \\
\beta_{g}\left(\frac{\Delta U_{g}^{2}}{2 a_{g}}+E U_{g l}-2 \underline{U}_{g}\right) & =0 \\
\beta_{b}\left(2 \underline{U}_{b}-\frac{\Delta U_{b}^{2}}{2 a_{b}}-E U_{b l}\right) & =0 \\
\gamma\left(2-\frac{\Delta U_{g}}{a_{g}} s_{h}^{I}-\left(1-\frac{\Delta U_{g}}{a_{g}}\right) s_{l}^{I}\right) & =0 \\
\lambda_{l} w_{l}^{I}=0 ; \lambda_{h} w_{h}^{I} & =0 \\
\epsilon_{h}\left(a_{g}-\Delta w_{h}^{I} s_{h}^{I}\right)=0 ; \epsilon_{l}\left(a_{g}-\Delta w_{l}^{I} s_{l}^{I}\right) & =0
\end{aligned}
$$$$
\frac{\partial L}{\partial \Delta w_{h}^{I}}=\frac{s_{h}^{I} \Delta w_{h}^{I}}{a_{g}^{2}}\left(G+\frac{\beta_{g}}{2} \Delta U_{g}\right)-\frac{s_{h}^{I} \Delta w_{h}^{I}}{a_{b}^{2}} \beta_{b} \Delta U_{b}+\frac{\Delta U_{g}}{a_{g}^{2}}\left(\Delta q-2 \Delta w_{h}^{I}\right)-\epsilon_{h}=0
$$

$$
\begin{aligned}
\frac{\partial L}{\partial s_{h}^{I}}=\left(\frac{s_{h}^{I} \Delta w_{h}^{I}}{a_{g}^{2}}+\frac{w_{h}^{I}}{a_{g} \Delta w_{h}^{I}}\right)(G+ & \left.\frac{\beta_{g}}{2} \Delta U_{g}\right)-\left(\frac{s_{h}^{I} \Delta w_{h}^{I}}{a_{b}^{2}}+\frac{w_{h}^{I}}{a_{b} \Delta w_{h}^{I}}\right) \beta_{b} \Delta U_{b} \\
& +\frac{\Delta U_{g}}{a_{g}^{2}}\left(\Delta q-\Delta w_{h}^{I}\right)-\gamma\left(\frac{\Delta U_{g}}{a_{g} \Delta w_{h}^{I}}\right)-\epsilon_{h}=0
\end{aligned}
$$

$$
\begin{aligned}
\frac{\partial L}{\partial \Delta w_{l}^{I}}=\frac{s_{l}^{I} \Delta w_{l}^{I}}{a_{g}}\left(-\frac{G}{a_{g}}-\frac{\beta_{g}}{2} \frac{\Delta U_{g}}{a_{g}}+\beta_{g}+\alpha\right) & -\frac{s_{l}^{I} \Delta w_{l}^{I}}{a_{b}} \beta_{b}\left(1-\frac{\Delta U_{b}}{a_{b}}\right)+ \\
& \left(1-\frac{\Delta U_{g}}{a_{g}}\right)\left(\frac{\Delta q-2 \Delta w_{l}^{I}}{a_{g}}\right)-\epsilon_{l}=0
\end{aligned}
$$




$$
\begin{aligned}
\frac{\partial L}{\partial s_{l}^{I}}= & \left(\frac{s_{l}^{I} \Delta w_{l}^{I}}{a_{g}}+\frac{w_{l}^{I}}{\Delta w_{l}^{I}}\right)\left(-\frac{G}{a_{g}}-\frac{\beta_{g}}{2} \frac{\Delta U_{g}}{a_{g}}+\beta_{g}+\alpha\right)-\left(\frac{s_{l}^{I} \Delta w_{l}^{I}}{a_{b}}+\frac{w_{l}^{I}}{\Delta w_{l}^{I}}\right) \\
& \beta_{b}\left(1-\frac{\Delta U_{b}}{a_{b}}\right)+\left(1-\frac{\Delta U_{g}}{a_{g}}\right) \frac{\left(\Delta q-\Delta w_{l}^{I}\right)}{a_{g}}-\frac{\gamma}{\Delta w_{l}^{I}}\left(1-\frac{\Delta U_{g}}{a_{g}}\right)-\epsilon_{l}=0 \\
\frac{\partial L}{\partial w_{h}^{I}}= & s_{h}^{I}\left(\frac{G}{a_{g}}+\frac{\beta_{g}}{2} \frac{\Delta U_{g}}{a_{g}}-\beta_{b} \frac{\Delta U_{b}}{a_{b}}\right)-\frac{\Delta U_{g}}{a_{g}}+\lambda_{h}=0 \\
\frac{\partial L}{\partial w_{l}^{I}}= & s_{l}^{I}\left(-\frac{G}{a_{g}}-\frac{\beta_{g}}{2} \frac{\Delta U_{g}}{a_{g}}+\beta_{b} \frac{\Delta U_{b}}{a_{b}}+\beta_{g}-\beta_{b}+\alpha\right)-\left(1-\frac{\Delta U_{g}}{a_{g}}\right)+\lambda_{l}=0
\end{aligned}
$$

Depending on parameters different solutions can occur. We focus on the case where in equilibrium:

$$
\begin{aligned}
& w_{h}^{I}>0 \text { and } w_{l}^{I}>0 \Rightarrow \lambda_{h}=\lambda_{l}=0 \\
& \beta_{b}=0 \Rightarrow E U_{b 1}<2 \underline{U}_{b} \\
& E U_{g l}=\underline{U}_{g} \Rightarrow \alpha>0 \\
& \beta_{g}>0 \Rightarrow \Delta U_{g}=\sqrt{2 a_{g} \underline{U}_{g}} \text { and } e_{g 1}^{I}=\sqrt{\frac{2 \underline{U}_{g}}{a_{g}}}
\end{aligned}
$$

It will be checked that these conditions are fulfilled at equilibrium and that condition (35) is implied by (34). Lemma 2 applies for $w_{h}$ and $w_{l}$. From (32), (34) and (35) we have $s_{h}^{I}=\frac{\Delta U_{g}}{G+\frac{\beta g}{2} \Delta U_{g}}$. From (28) and (35) we get $\frac{\Delta U_{g}}{a_{g}^{2}}\left(\Delta q-\Delta w_{h}^{I}\right)=\epsilon_{h}$. Similarly, from (30) and (33) we get: $\left(1-\frac{\Delta U_{g}}{a_{g}}\right) \frac{1}{a_{g}}\left(\Delta q-\Delta w_{l}^{I}\right)=\epsilon_{l}$. Lemma 2 then implies $\epsilon_{h}=\epsilon_{l}=0$. Substituting (28) in (29) yields $\gamma=\frac{\Delta w_{h}^{2}}{a_{g}}+w_{h}^{I} \frac{\beta_{g}}{2}+\frac{w_{h}^{I}}{\Delta U_{g}} G$. Applying (34) and (35) to (32), we get $G=\frac{\Delta U_{g}}{s_{h}^{I}}-\frac{\beta_{g}}{2} \Delta U_{g}$. Hence, $\gamma=\frac{w_{h}^{I}}{s_{h}^{I}}+\frac{\Delta q^{2}}{a_{g}}$.

From (32), (33) and (34) it follows that $\beta_{g}+\alpha=\frac{1}{s_{l}^{I}}\left(1-\frac{\Delta U_{g}}{a_{g}}\right)+\frac{\Delta U_{g}}{a_{g} s_{h}^{I}}$. Since $\frac{\Delta U_{g}}{a_{g}}=e_{g 1}^{I} \leq 1$ we have $\beta_{g}+\alpha>0$. Substituting in (30) and (31), we get $\gamma=\frac{w_{l}^{I}}{s_{l}^{I}}+\frac{\Delta q^{2}}{a_{g}}$. Equating these two expressions for $\gamma$ it follows that $\left(s_{h}^{I}, s_{l}^{I}\right)$ is such that: $\frac{w_{h}^{I}}{s_{h}^{I}}=\frac{w_{l}^{I}}{s_{l}^{I}}$. Moreover we have: $\frac{\Delta U_{g}}{a_{g}} s_{h}^{I}+\left(1-\frac{\Delta U_{g}}{a_{g}}\right) s_{l}^{I}=2(\gamma>0)$. Given these specifications as well as (36) and (37) we 
find:

$$
\begin{aligned}
& s_{l}^{I}=\frac{2}{\left(1+\sqrt{\frac{2 \underline{\underline{U}} a_{g}}{a_{g}}}\left(\sqrt{\sqrt{\frac{2 a_{g}}{\underline{\underline{G}}_{g}}}+1}-1\right)\right)} \\
& s_{h}^{I}=\frac{2 \sqrt{\sqrt{\frac{2 a_{g}}{\underline{U}_{g}}}+1}}{\left(1+\sqrt{\frac{2 \underline{\underline{U}}_{g}}{a_{g}}}\left(\sqrt{\sqrt{\frac{2 a_{g}}{\underline{U}_{g}}}+1}-1\right)\right)}
\end{aligned}
$$

Using $\frac{w_{h}^{I}}{s_{h}^{I}}=\frac{w_{l}^{I}}{s_{l}^{I}}$ we find that

$$
w_{h}^{I}=w_{l}^{I} \sqrt{\sqrt{\frac{2 a_{g}}{\underline{U}_{g}}}+1}
$$

and using (36) we get $\frac{\left(s_{l}^{I} \Delta q\right)^{2}}{2 a_{g}}+s_{l}^{I} w_{l}^{I}=\underline{U}_{g}$. Hence,

$$
w_{l}^{I}=\frac{\underline{U}_{g}}{s_{l}^{I}}-\frac{s_{l}^{I} \Delta q^{2}}{2 a_{g}} .
$$

Profit is positive for the firm given these specifications. We have $\pi^{I}=e_{g 1}^{I}\left(\Delta q-w_{h}^{I}\right)+$ $\left(1-e_{g 1}^{I}\right) w_{l}^{I}+2 q$. Inserting $w_{h}^{I}, s_{l}^{I}$ and $w_{l}^{I}$ yields $\pi^{I}=e_{g 1}^{I} \Delta q-\frac{a_{g} e_{g 1}^{I 2}}{2}\left(1+e_{g 1}^{I}\left(\sqrt{\frac{2}{e_{g 1}^{I}}+1}-1\right)\right)+$ $\frac{\Delta q^{2}}{a_{g}}+2 q$. A sufficient condition is $e_{g 1}^{I} \frac{\Delta q}{q}-\frac{a_{g} e_{g 1}^{I 2}}{2 q}\left(1+e_{g 1}^{I}\left(\sqrt{\frac{2}{e_{g 1}^{I}}+1}-1\right)\right)+2>0$. As in the proof of Proposition 1, let $a=\frac{a_{g}}{q}$ and $\Delta=\frac{\Delta q}{q}$ with $a \geq 37.5$ and $\Delta \leq 5$ as given by Assumption A.2. Then, $e_{g 1}^{I}=\frac{1}{a} \sqrt{2 a+\Delta^{2}}$. Thus, profit is positive if $g(a, \Delta)=$ $\Delta e_{g 1}^{I}(a, \Delta)-\frac{a e_{g 1}^{I 2}(a, \Delta)}{2}\left(1+e_{g 1}^{I}(a, \Delta)\left(\sqrt{\frac{2}{e_{g 1}^{I}(a, \Delta)}+1}-1\right)\right)+2>0$. It is $\frac{\partial g(a, \Delta)}{\partial a}>0$ and $\frac{\partial g(a, \Delta)}{\partial \Delta}>0$. It remains to be shown that $g(a, \Delta)$ is positive for the lowest values $a$ and $\Delta$. We have $g(37.5,0) \sim 0.51$.

Condition (34) is satisfied if $E U_{b 1}=\frac{1}{2 a_{b}}\left(\frac{\Delta q^{2}}{2 a_{b}}\left(s_{h}^{I 2}-s_{l}^{I 2}\right)+s_{h}^{I} w_{h}^{I}-s_{l}^{I} w_{l}^{I}\right)^{2}+\frac{\left(s_{l}^{I} \Delta q\right)^{2}}{2 a_{b}}+$ $s_{l}^{I} w_{l}^{I}<2 \underline{U}_{b}$. We have: $s_{h}^{I 2}-s_{l}^{I 2}=s_{l}^{I 2} \sqrt{\frac{2 a_{g}}{\underline{U}_{g}}} ; s_{l}^{I} w_{l}^{I}=\underline{U}_{g}-\frac{s_{l}^{I 2} \Delta q^{2}}{2 a_{g}}$ and $s_{h}^{I} w_{h}^{I}=s_{l}^{I} w_{l}^{I}\left(\sqrt{\frac{2 a_{g}}{\underline{U}_{g}}}+1\right)$. 
The condition simplifies to $\frac{\Delta q^{2}\left(\frac{s_{l}^{I 2}}{2}-1\right)+\frac{a_{g}}{\underline{U}_{g}}\left(q-\frac{\Delta q^{2}}{2 a_{g}}\left(s_{l}^{I 2}-1\right)+\frac{s_{l}^{I 2} \Delta q^{2}}{2} \frac{1}{a_{b}}\right)^{2}}{\left(q+\frac{\Delta q^{2}}{2 a_{g}}\left(s_{l}^{I 2}-1\right)\right)}<a_{b}$. Since the $L H S<a_{g}$ and by assumption $a_{g}<a_{b}$ this condition is always fulfilled.

We now check $\beta_{g}>0$. We have $\beta_{g}=\frac{2}{s_{h}^{I}}-\frac{2}{\Delta U_{g}} G$. Inserting values for $G, \Delta U_{g}$ and $\gamma$ we must have $a_{g} \frac{\left(2-s_{l}^{I}\right)}{\left(s_{h}^{I}-s_{l}^{I}\right)}+2 w_{h}^{I}\left(s_{h}^{I}-s_{l}^{I}\right)+\frac{\Delta q^{2}}{a_{g}} s_{h}^{I}\left(s_{h}^{I}-s_{l}^{I}\right)>s_{h}^{I} \Delta q$. Inserting values for $s_{h}^{I}$ and $s_{l}^{I}$ we get $\sqrt{2 a_{g} \underline{U}_{g}}+2 \underline{U}_{g}(y-1)+2 \underline{U}_{g}\left(1+\sqrt{\frac{2 \underline{U}_{g}}{a_{g}}}(y-1)\right) y(y-1)>2 y \Delta q$ with $y=\sqrt{\sqrt{\frac{2 a_{g}}{\underline{U}_{g}}}+1}$. A sufficient condition for this to be fulfilled is $3 \sqrt{2 a_{g} \underline{U}_{g}}>2 y \Delta q$ or $4 a_{g}^{2} q^{3}+\frac{38}{9} a_{g} q^{2} \Delta q^{2}+\frac{115}{81} q \Delta q^{4}+\frac{25}{162} \frac{\Delta q^{6}}{a_{g}}>\frac{32}{81} \Delta q^{4} a_{g}$. A sufficient condition for this is $4 a_{g}^{2} q^{3}+$ $\frac{38}{9} a_{g} q^{2} \Delta q^{2} \geq \frac{32}{81} \Delta q^{4} a_{g}$ or $a_{g} \geq \frac{\Delta q^{2}}{9 q}\left(\frac{8}{9} \frac{\Delta q^{2}}{q^{2}}-\frac{19}{2}\right)$. Given assumption A.2 we have $a_{g} \geq 37.5 q$. We thus have to show $37.5 \geq \frac{\Delta q^{2}}{9 q^{2}}\left(\frac{8}{9} \frac{\Delta q^{2}}{q^{2}}-\frac{19}{2}\right)$. This is fulfilled for $\frac{\Delta q}{q}<5$ as given by A.2.

We now need to check $\alpha>0$. We know $\beta_{g}+\alpha=\frac{1}{s_{l}^{I}}\left(1-\frac{\Delta U_{g}}{a_{g}}\right)+\frac{\Delta U_{g}}{a_{g} s_{h}^{I}}>0$ and $\beta_{g}=\frac{1}{s_{h}^{I}}-\frac{1}{\Delta U_{g}}\left(\Delta q-w_{h}^{I}+w_{l}^{I}-\left(\frac{w_{l}^{I}}{s_{l}^{I}}+\frac{\Delta q^{2}}{a_{g}}\right)\left(s_{h}^{I}-s_{l}^{I}\right)\right)>0$. Thus we need to show $\beta_{g}<$ $\frac{1}{s_{l}^{I}}\left(1-\frac{\Delta U_{g}}{a_{g}}\right)+\frac{\Delta U_{g}}{a_{g} s_{h}^{I}}$. Substituting $w_{h}^{I}$ and $w_{l}^{I}$ this is equivalent to $\frac{2}{\Delta U_{g}}\left(\sqrt{\sqrt{\frac{2 a_{g}}{\underline{U}_{g}}}+1}-1\right) \frac{\underline{U}_{g}}{s_{l}^{I}}<$ $\frac{\Delta q}{\Delta U_{g}}+\frac{1}{s_{l}^{I}}-\frac{1}{s_{h}^{I}}+\frac{\Delta U_{g}}{a_{g} s_{h}^{I}}-\frac{\Delta U_{g}}{s_{l}^{I} a_{g}}$. Substituting $\Delta U_{g}=\sqrt{2 a_{g} \underline{U}_{g}}$ we get $\left(\sqrt{\sqrt{\frac{2 a_{g}}{\underline{U}_{g}}}+1}-1\right)<$ $\frac{\Delta q}{2 \underline{U}_{g}} s_{l}^{I}+\left(\sqrt{\frac{a_{g}}{2 \underline{U}_{g}}}-1\right)\left(1-\frac{s_{l}^{I}}{s_{h}^{I}}\right)$. Substituting $s_{l}^{I}, s_{h}^{I}$, and $y:=\sqrt{\sqrt{\frac{2 a_{g}}{\underline{U}_{g}}}+1}>1$ we get $\Delta q>\underline{U}_{g} \frac{(y-1)}{y}\left(4-\sqrt{\frac{a_{g}}{2 \underline{U}_{g}}}\right)$. This is always fulfilled for $\sqrt{\frac{2 \underline{\underline{U}}_{g}}{a_{g}}}=e_{g 1}^{I} \leq \frac{1}{4}$. For $e_{g 1}^{I}>\frac{1}{4}$ we have to show that $\left(\Delta q-4 \underline{U}_{g}+\sqrt{\frac{1}{2} a_{g} \underline{U}_{g}}\right) \sqrt{\sqrt{\frac{2 a_{g}}{\underline{U}_{g}}}+1}+\underline{U}_{g}\left(4-\sqrt{\frac{a_{g}}{2 \underline{U}_{g}}}\right)>0$. A sufficient condition is $\Delta q-4 \underline{U}_{g}+\sqrt{\frac{1}{2} a_{g} \underline{U}_{g}}>0$ and substituting $\underline{U}_{g}$ we get $\Delta q+\sqrt{\frac{1}{2} a_{g} q+\frac{\Delta q^{2}}{4}}>4 q+\frac{2 \Delta q^{2}}{a_{g}}$. The LHS is increasing in $a_{g}$ and the RHS decreasing. Given assumption A.2, a sufficient condition is thus to set $a_{g}=\frac{75}{2} q$. This gives us $\sqrt{\frac{75}{4} q^{2}+\frac{\Delta q^{2}}{4}}>4 q+\frac{4 \Delta q^{2}}{75 q}-\Delta q$ or $2.75+\frac{\Delta q}{q}\left(8+\frac{8 \Delta q^{2}}{75 q^{2}}\right)-\frac{\Delta q^{2}}{q^{2}}\left(\frac{32}{75}+\frac{3}{4}-\frac{16 \Delta q^{2}}{(75)^{2} q^{2}}\right)>0$. For $\frac{\Delta q}{q} \leq 5$ as given by Assumption A.2, this is always fulfilled.

We finish with $e_{g h}^{I}=\frac{s_{h}^{I} \Delta q}{a_{g}}<1$ which implies $e_{g l}^{I}=\frac{s_{l}^{I} \Delta q}{a_{g}}<1$. We have to have $a_{g}>s_{h}^{I} \Delta q$ which is equivalent to $a_{g}-\sqrt{2 a_{g} \underline{U}_{g}}+\sqrt{2 a_{g} \underline{U}_{g}} \sqrt{\sqrt{\frac{2 a_{g}}{\underline{G}_{g}}}+1}>2 \Delta q \sqrt{\sqrt{\frac{2 a_{g}}{\underline{U}_{g}}}+1}$. Given $e_{g 1}^{I}<1$ we have $a_{g}>\sqrt{2 a_{g} \underline{U}_{g}}$. A sufficient condition is thus $\sqrt{2 a_{g} \underline{U}_{g}} \geq 2 \Delta q$ or $a_{g} \geq \frac{3}{2} \frac{\Delta q^{2}}{q}$. Given 
assumption A.2 we have $a_{g} \geq 37.5 q$. We thus have to show $37.5 \geq \frac{3}{2} \frac{\Delta q^{2}}{q^{2}}$. This is fulfilled for $\frac{\Delta q}{q} \leq 5$ as given by assumption A.2. QED 


\section{Proof of Proposition 3}

Profit with up-or-out is higher than profit with standard promotion by merit if and only if:

$$
\frac{2 e_{g 1}^{U}}{1+e_{g 1}^{U}}\left(\Delta q-w_{h}^{U}\right)+2 q>e_{g 1}^{I}\left(\Delta q-w_{h}^{I}\right)-\left(1-e_{g 1}^{I}\right) w_{l}^{I}+2 q
$$

Defining $\Delta \Pi$ as the difference in profits between up-or-out and internal labor market and using that $e_{g 1}^{I}=\frac{1}{\sqrt{2}} e_{g 1}^{U}$, we find

$$
\Delta \Pi=\frac{2 e_{g 1}^{U}}{1+e_{g 1}^{U}}\left(\Delta q-w_{h}^{U}\right)-\frac{e_{g 1}^{U}}{\sqrt{2}}\left(\Delta q-w_{h}^{I}\right)+\left(1-\frac{e_{g 1}^{U}}{\sqrt{2}}\right) w_{l}^{I}
$$

Using from Proposition 1

$$
e_{g 1}^{U}=\sqrt{2} \sqrt{\frac{2 \underline{U}}{a_{g}}}
$$

and from Proposition 2,

$$
w_{h}^{I}=w_{l}^{I} \sqrt{\frac{2 \sqrt{2}}{e_{g 1}^{U}}+1} \text { and } s_{l}^{I}=\frac{2}{1+\frac{e_{g 1}^{U}}{\sqrt{2}}\left(\sqrt{\frac{2 \sqrt{2}}{e_{g 1}^{U}}+1}-1\right)}
$$

we obtain:

$$
\Delta \Pi=\left(\frac{2 e_{g 1}^{U}}{1+e_{g 1}^{U}}-\frac{e_{g 1}^{U}}{\sqrt{2}}\right) \Delta q-\frac{2 e_{g 1}^{U}}{1+e_{g 1}^{U}} w_{h}^{U}+2 \frac{w_{l}^{I}}{s_{l}^{I}} .
$$

Furthermore, we have

$$
\begin{aligned}
w_{h}^{U} & \left.=\frac{e_{g 1}^{U 2}}{1+e_{g 1}^{U}} a_{g}-\frac{\left(2 e_{g 1}^{U}+1\right)}{e_{g 1}^{U}\left(1+e_{g 1}^{U}\right)} \frac{\Delta q^{2}}{2 a_{g}}+\frac{e_{g 1}^{U}}{1+e_{g 1}^{U}} q \text { (from Proposition } 1\right) \\
w_{l}^{I} & =\frac{e_{g 1}^{U 2}}{4 s_{l}^{I}} a_{g}-\frac{s_{l}^{I} \Delta q^{2}}{2 a_{g}} \text { (from Proposition 2) }
\end{aligned}
$$


Hence,

$$
\Delta \Pi=\left(\frac{2 e_{g 1}^{U}}{1+e_{g 1}^{U}}-\frac{e_{g 1}^{U}}{\sqrt{2}}\right) \Delta q+\frac{e_{g 1}^{U 2}}{\left(1+e_{g 1}^{U}\right)^{2}} \frac{a_{g}}{8}\left[\left(1+\frac{e_{g 1}^{U}}{\sqrt{2}}\left(\sqrt{\frac{2 \sqrt{2}}{e_{g 1}^{U}}+1}-1\right)\right)^{2}\left(1+e_{g 1}^{U}\right)^{2}-16\left(e_{g 1}^{U}+\frac{\underline{U}_{g}}{a_{g}}\right)\right] .
$$

In a way similar to the proof of Proposition 1, we re-scale the problem in function of $q$ with $a=\frac{a_{g}}{q}$ and $\Delta=\frac{\Delta q}{q}$. Given A.2 we have $a \geq 37.5$ and $\Delta \leq 5$. Then,

$$
e_{g 1}^{U}=\frac{\sqrt{2}}{a} \sqrt{2 a+\Delta^{2}} \in\left(0, \frac{10 \sqrt{2}}{37.5}\right]
$$

It is straightforward to check that $e_{g 1}^{U}$ is decreasing and convex in $a$, and that it is increasing and convex in $\Delta$. It hence reaches its maximum for $a=37.5$ and $\Delta=5$. Equation (47) is equivalent to

$$
\frac{\Delta \Pi(a, \Delta)}{q}=\left(\frac{2 e_{g 1}^{U}}{1+e_{g 1}^{U}}-\frac{e_{g 1}^{U}}{\sqrt{2}}\right) \Delta+\frac{e_{g 1}^{U 2}}{\left(1+e_{g 1}^{U}\right)^{2}} \frac{a}{8}\left[\left(1+\frac{e_{g 1}^{U}}{\sqrt{2}}\left(\sqrt{\frac{2 \sqrt{2}}{e_{g 1}^{U}}+1}-1\right)\right)^{2}\left(1+e_{g 1}^{U}\right)^{2}-16\left(e_{g 1}^{U}+\frac{1}{a}+\frac{\Delta^{2}}{2 a^{2}}\right)\right] .
$$

Let $\Delta \pi(a, \Delta)=\frac{\Delta \Pi(a, \Delta)}{q}$. Note that independently from $\Delta \in[0,5], \lim _{a \rightarrow+\infty} \Delta \pi>0$ as $\lim _{a \rightarrow+\infty} e_{g 1}^{U 2} \frac{a}{8}=\frac{1}{2}$. By continuity it is still true for lower values of $a$. When $a$ is very large so that success is difficult, the firm's profit is always higher with up-or-out than with an internal labor market.

We now prove that for low values of $\Delta$ it exists $a^{l}(\Delta)>37.5$ such that $\Delta \pi(a, \Delta) \geq 0$ if and only if $a \geq a^{l}(\Delta)$. Let $f(a, \Delta)=\left(1+\frac{e_{g 1}^{U}}{\sqrt{2}}\left(\sqrt{\frac{2 \sqrt{2}}{e_{g 1}^{U}}+1}-1\right)\right)^{2}\left(1+e_{g 1}^{U}\right)^{2}$ and $d(a, \Delta)=$ $4 \sqrt{2} \frac{\Delta}{a}\left(1+e_{g 1}^{U}\right) \frac{2 \sqrt{2}-1-e_{g 1}^{U}}{e_{g 1}^{U}}$. From $(48) \Delta \pi(a, \Delta)>0$ with $a \geq 37.5$ and $\Delta \in(0,5]$ is equivalent to

$$
f\left(e_{g 1}^{U}(a, \Delta)\right)+d(a, \Delta)>16\left(e_{g 1}^{U}(a, \Delta)+\frac{1}{a}+\frac{\Delta^{2}}{2 a^{2}}\right)
$$


This part of the proof is done in two steps. First we consider the case $\Delta=0$ and show that there exists a unique $a^{l}(0)>37.5$. Second, we consider the case $\Delta>0$. We show that there is a critical value $\Delta^{l}$ such that for all $\Delta<\Delta^{l}$ it exists $a^{l}(\Delta)>37.5$ so that $\Delta \pi \geq 0$ if and only if $a \geq a^{l}(\Delta)$. To conclude we show that for all $\Delta>\Delta^{l}$ we have $\Delta \pi>0$ for all $a \geq 37.5$.

Consider the case $\Delta=0$ so that $e_{g 1}^{U}=\frac{2}{\sqrt{a}}$ and $d(a, \Delta)=0$. From (49) $\Delta \Pi>0$ is equivalent to $f\left(\frac{2}{\sqrt{a}}\right)>16\left(\frac{2}{\sqrt{a}}+\frac{1}{a}\right)$. The functions $f\left(\frac{2}{\sqrt{a}}\right)$ and $16\left(\frac{2}{\sqrt{a}}+\frac{1}{a}\right)$ can cross only once, twice or none because they are both decreasing and convex in $a$. Since $f\left(\frac{2}{\sqrt{37.5}}\right)<$ $16\left(\frac{2}{\sqrt{37.5}}+\frac{1}{37.5}\right)$, while $\lim _{a \rightarrow+\infty} f\left(\frac{2}{\sqrt{a}}\right)=1>\lim _{a \rightarrow+\infty} 16\left(\frac{2}{\sqrt{a}}+\frac{1}{a}\right)=0$ they cross once. There is a unique $a^{l}>37.5$ so that $\Delta \pi \geq 0$ if and only if $a \geq a^{l}$. We have $a^{l} \sim 182.95$ for $\Delta=0$.

We now turn to the case $\Delta>0$. One can check after tedious computations that for all $\Delta \in(0,5], f\left(e_{g 1}^{U}(a, \Delta)\right)$ and $d(a, \Delta)$ are decreasing and convex in $a \geq 37.5$. Therefore, $f\left(e_{g 1}^{U}(a, \Delta)\right)+d(a, \Delta)$ is decreasing and convex in $a$. We can thus apply the same reasoning as before. Since $\lim _{a \rightarrow+\infty} \Delta \pi(a, \Delta)>0 \forall \Delta \in[0,5]$, we just need to show that it exists a $\Delta^{l}>0$ so that $\Delta \pi(37.5, \Delta)<0 \forall \Delta<\Delta^{l}$. The function $\Delta \pi(37.5, \Delta)$ is continuous in $\Delta$. Moreover $\Delta \pi(37.5,0)<0$ while $\Delta \pi(37.5,5)>0$ so that there is at least one $\Delta^{l} \in(0,5]$ so that $\Delta \pi(37.5, \Delta)=0$. The following graph of $\Delta \pi(37.5, \Delta)$ shows that $\Delta^{l}$ is unique with $\Delta^{l} \sim 2.07$.

$<$ Figure 1 about here. $>$

Finally, note that by construction $\Delta \pi(37.5, \Delta)<0$ for all $\Delta<\Delta^{l}$. Hence, for all $\Delta<\Delta^{l}$ it exists $a^{l}(\Delta)>37.5$ so that $\Delta \pi \geq 0$ if and only if $a \geq a^{l}(\Delta)$. The following graph shows that for $\Delta>\Delta^{l}$ we have $\Delta \pi>0$ for all $a \geq 37.5$.

$<$ Figure 2 about here. $>$

QED 
Figure 1

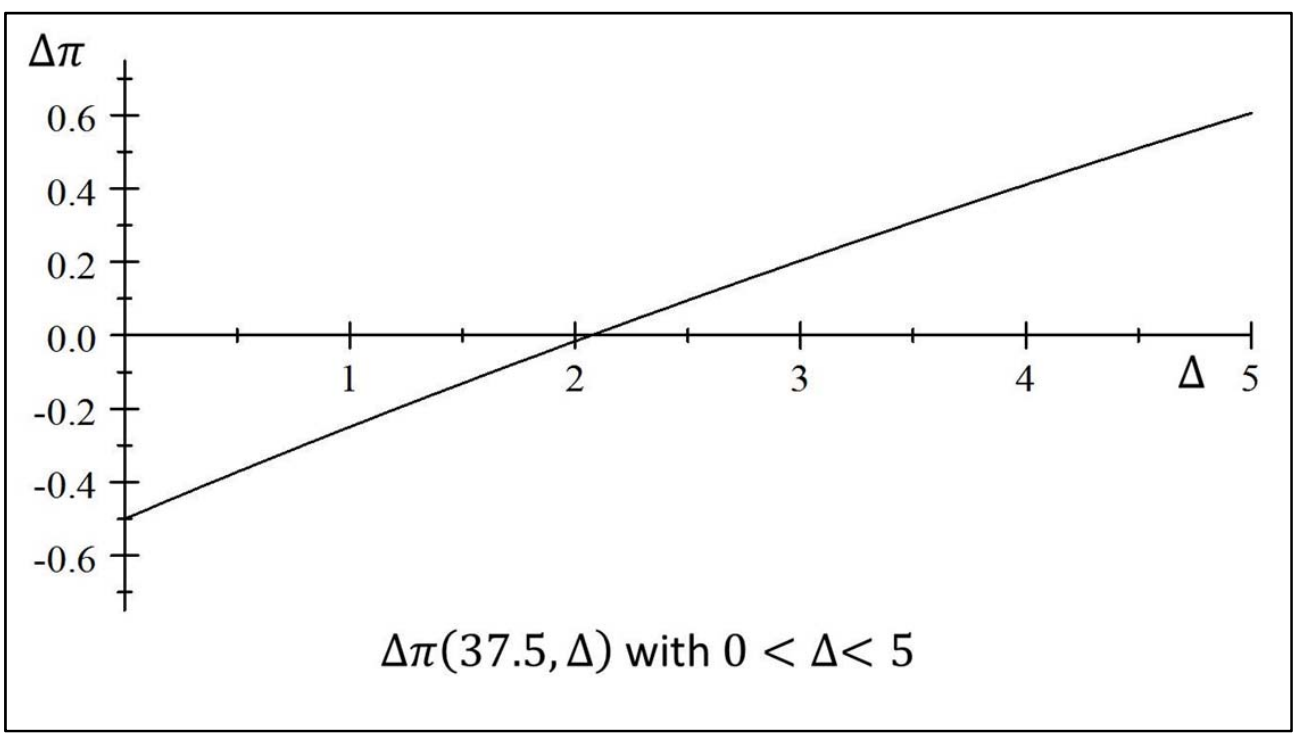

Figure 2

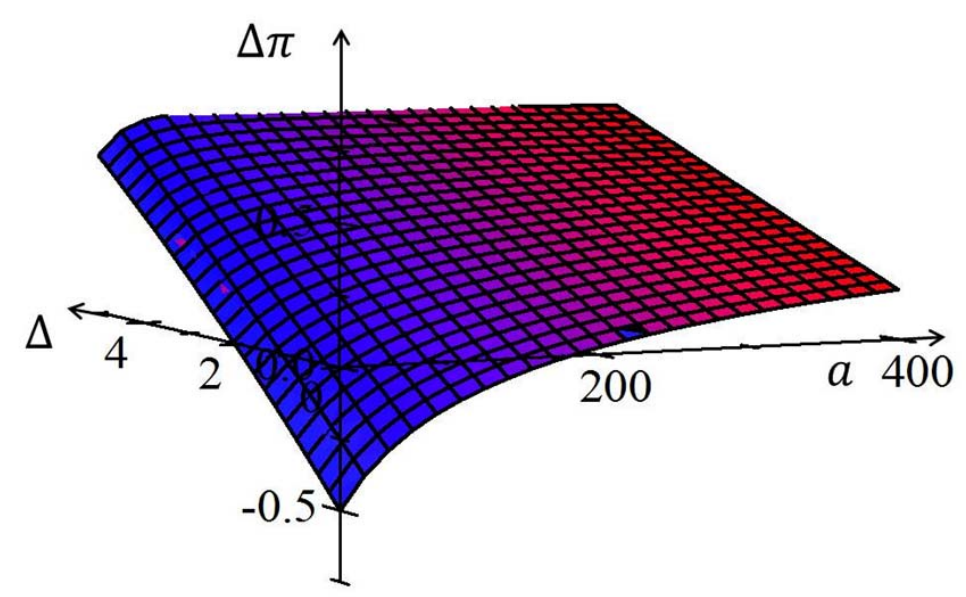

$\Delta \pi(a, \Delta)$ with $a>37.5$ and $0<\Delta<5$ 
Table 1: Junior / senior ratios, top 50 U.S. economic departments

\begin{tabular}{|c|c|c|c|c|c|}
\hline & University & Full Prof. & Assoc. Prof. & Ass. Prof. & $\begin{array}{c}\text { (Assoc. + Ass. Prof) / Full } \\
\text { Professor }\end{array}$ \\
\hline 1 & Arizona State & 20 & 6 & 8 & 0.7 \\
\hline 2 & Berkeley & 41 & 4 & 9 & 0.3 \\
\hline 3 & Boston U & 21 & 7 & 12 & 0.9 \\
\hline 4 & Brown & 15 & 5 & 9 & 0.9 \\
\hline 5 & Columbia & 33 & 4 & 14 & 0.5 \\
\hline 6 & Cornell & 27 & 0 & 7 & 0.3 \\
\hline 7 & Dartmouth College & 15 & 5 & 4 & 0.6 \\
\hline 8 & Duke & 29 & 9 & 10 & 0.7 \\
\hline 9 & Georgetown & 12 & 8 & 6 & 1.2 \\
\hline 10 & Harvard & 37 & 3 & 11 & 0.4 \\
\hline 11 & Indiana & 12 & 8 & 1 & 0.8 \\
\hline 12 & Iowa State & 26 & 11 & 3 & 0.5 \\
\hline 13 & Johns Hopkins & 13 & 1 & 3 & 0.3 \\
\hline 14 & Michigan State & 27 & 13 & 7 & 0.7 \\
\hline 15 & MIT & 31 & 3 & 6 & 0.3 \\
\hline 16 & NYU & 34 & 4 & 14 & 0.5 \\
\hline 17 & Northwestern & 23 & 5 & 13 & 0.8 \\
\hline 18 & Ohio State & 25 & 8 & 8 & 0.6 \\
\hline 19 & Penn State & 18 & 4 & 4 & 0.4 \\
\hline 20 & Princeton & 45 & 0 & 11 & 0.2 \\
\hline 21 & Purdue & 9 & 4 & 7 & 1.2 \\
\hline 22 & Rice & 14 & 3 & 4 & 0.5 \\
\hline 23 & Rutgers & 22 & 6 & 3 & 0.4 \\
\hline 24 & Stanford & 34 & 6 & 17 & 0.7 \\
\hline 25 & Syracuse & 17 & 4 & 7 & 0.6 \\
\hline 26 & $\mathrm{U}$ of Arizona & 11 & 5 & 4 & 0.8 \\
\hline 27 & U CA, Irvine & 8 & 6 & 11 & 2.1 \\
\hline 28 & U CA, Santa Barbara & 15 & 1 & 6 & 0.5 \\
\hline 29 & UCLA & 24 & 8 & 12 & 0.8 \\
\hline 30 & U California - San Diego & 25 & 7 & 17 & 1 \\
\hline 31 & U Florida & 14 & 3 & 2 & 0.4 \\
\hline 32 & U Illinois & 16 & 2 & 7 & 0.6 \\
\hline 33 & U Iowa & 12 & 3 & 5 & 0.7 \\
\hline 34 & U Minnesota & 18 & 3 & 7 & 0.6 \\
\hline 35 & U North Carolina & 8 & 6 & 9 & 1.9 \\
\hline 36 & U Pennsylvania & 17 & 3 & 11 & 0.8 \\
\hline 37 & U Pittsburgh & 13 & 4 & 8 & 0.9 \\
\hline 38 & U Rochester & 8 & 3 & 11 & 1.8 \\
\hline 39 & U Southern California & 14 & 4 & 3 & 0.5 \\
\hline 40 & U Texas - Austin & 16 & 6 & 12 & 1.1 \\
\hline 41 & U Virginia & 16 & 4 & 14 & 1.1 \\
\hline 42 & U Washington & 14 & 5 & 6 & 0.8 \\
\hline 43 & U WI-Madison & 15 & 3 & 9 & 0.8 \\
\hline 44 & U of Chicago & 26 & 0 & 5 & 0.2 \\
\hline 45 & U of Maryland & 16 & 7 & 11 & 1.1 \\
\hline 46 & U of Oregon & 12 & 3 & 4 & 0.6 \\
\hline 47 & Utah & 13 & 6 & 5 & 0.8 \\
\hline 48 & Vanderbilt U & 19 & 6 & 6 & 0.6 \\
\hline 49 & Washington U St Louis & 23 & 5 & 5 & 0.4 \\
\hline \multirow[t]{2}{*}{50} & Yale & 37 & 2 & 12 & 0.4 \\
\hline & Mean & 20.2 & 4.72 & 8 & 0.7 \\
\hline
\end{tabular}

Sources: University homepages (June 2009). The 50 top U.S. econ. dept's are listed according to Dusansky and Vernon (1998). Information for Michigan, UC-Davis, Cal Tech, Texas A\&M, Boston College, Carnegie Mellon, Virginia Tech, Colorado, Houston, N. Carolina State, SUNY-Albany was not available. We used the next-highest ranked departments. 
Table 2: Junior / senior ratios, top 50 economic departments, France

\begin{tabular}{|c|c|c|c|c|c|}
\hline & University & \# Researchers & $\begin{array}{c}\text { Share Prof. } \\
\text { rank) }\end{array}$ & $\begin{array}{c}\text { Share "Non-Prof." } \\
\text { (B rank) }\end{array}$ & B rank/ A rank \\
\hline 1 & Toulouse TSE & 125 & 52 & 48 & 0.9 \\
\hline 2 & PSE-Paris 1 & 214 & 46 & 54 & 1.2 \\
\hline 3 & Crest-ENSAE & 67 & 83 & 17 & 0.2 \\
\hline 4 & HEC & \multicolumn{4}{|c|}{ not applicable because business schools have no B rank } \\
\hline 5 & AIX Marseille & 114 & 47 & 53 & 1.1 \\
\hline 6 & Ecole Polytechnique & 33 & 66 & 34 & 0.5 \\
\hline 7 & Cergy Pontoise & 37 & 28 & 72 & 2.5 \\
\hline 8 & IEP Paris & 9 & 65 & 35 & 0.5 \\
\hline 9 & Nancy 2 Strasbourg & 95 & 32 & 68 & 2.1 \\
\hline 10 & Paris 9 & 124 & 36 & 64 & 1.8 \\
\hline 11 & Caen-Rennes & 121 & 34 & 66 & 2 \\
\hline 12 & Paris 10 & 80 & 30 & 70 & 2.4 \\
\hline 13 & Montpellier 1 - INRA & 62 & 31 & 69 & 2.3 \\
\hline 14 & Le Mans & 18 & 40 & 60 & 1.5 \\
\hline 15 & Paris 2 & 41 & 56 & 44 & 0.8 \\
\hline 16 & Clermont 1 & 32 & 27 & 73 & 2.8 \\
\hline 17 & Lille 1 Polytech Lille & 153 & 28 & 72 & 2.6 \\
\hline 18 & Bordeaux 4 & 72 & 34 & 66 & 2 \\
\hline 19 & Grenoble 2 - INRA & 128 & 32 & 68 & 2.1 \\
\hline 20 & Lyon 2 & 70 & 33 & 67 & 2 \\
\hline 21 & ENS Cachan & 7 & 46 & 55 & 1.2 \\
\hline 22 & INRA Vers-Grig & 12 & 46 & 54 & 1.2 \\
\hline 23 & INRA Ivry & 37 & 34 & 66 & 2 \\
\hline 24 & Nantes & 23 & 24 & 76 & 3 \\
\hline 25 & Evry & 18 & 47 & 53 & 1.1 \\
\hline 26 & INRA Dijon & 11 & 36 & 64 & 1.7 \\
\hline 27 & Montpellier 3 & 10 & 5 & 95 & 18 \\
\hline 28 & Besancon & 24 & 33 & 67 & 2 \\
\hline 29 & Lille 3 & 11 & 14 & 86 & 6.3 \\
\hline 30 & INRA Rennes & 12 & 42 & 58 & 1.4 \\
\hline 31 & Reims & 32 & 11 & 89 & 8 \\
\hline 32 & Lille 2 & 13 & 27 & 73 & 2.7 \\
\hline 33 & Cired & 14 & 37 & 63 & 1.7 \\
\hline 34 & Perpignan & 12 & 9 & 91 & 10.5 \\
\hline 35 & Cnam & 7 & 57 & 43 & 0.8 \\
\hline 36 & Nice & 83 & 42 & 58 & 1.4 \\
\hline 37 & Orleans & 34 & 37 & 63 & 1.7 \\
\hline 38 & Strasbourg 3 & 13 & 34 & 66 & 2 \\
\hline 39 & Paris 13 & 45 & 43 & 57 & 1.3 \\
\hline 40 & Toulon & 11 & 27 & 73 & 2.7 \\
\hline 41 & St Etienne & 22 & 23 & 77 & 3.4 \\
\hline 42 & Marne La Vallee & 11 & 29 & 71 & 2.5 \\
\hline 43 & Tours & - & - & - & - \\
\hline 44 & Versailles & 24 & 29 & 71 & 2.4 \\
\hline 45 & Angers & 18 & 33 & 67 & 2 \\
\hline 46 & Dijon & 65 & 29 & 71 & 2.4 \\
\hline 47 & Antilles Guyane & 22 & 37 & 63 & 1.7 \\
\hline 48 & La Reunion & 19 & 11 & 90 & 8.5 \\
\hline 49 & Brest & 21 & 12 & 88 & 7.2 \\
\hline 50 & Limoges & 18 & 22 & 78 & 3.5 \\
\hline & Mean & 46.75 & 34.8 & 65.2 & 2.8 \\
\hline
\end{tabular}

Source: Bosquet et al (2010). Rank A are senior professors. Universities and other research institutions usually operate joint research facilities in a given city. In some cities there are more than one of these facilities. Departments are listed by rank, as we also look into the ratios for the top 20 departments. 